\title{
CHHC and ${ }^{1} \mathrm{H}-1 \mathrm{H}$ Magnetization Exchange: Analysis by Experimental Solid-State NMR and 11-Spin Density-Matrix Simulations
}

\author{
Mihaela Aluas ${ }^{1}$, Carmen Tripon ${ }^{2}$, John M. Griffin ${ }^{3}$, Xenia Filip ${ }^{1}$, Vladimir Ladizhansky ${ }^{4}$, \\ Robert G. Griffin ${ }^{5}$, Steven P. Brown ${ }^{3}$, and Claudiu Filip, ${ }^{2}{ }^{*}$ \\ ${ }^{1}$ Physics Department, Babes-Bolyai University, 400084 Cluj, Romania \\ ${ }^{2}$ National Institute for R\&D of Isotopic and Molecular Technologies, P.O. Box 700, 400293 Cluj, \\ Romania \\ ${ }^{3}$ Department of Physics, University of Warwick, Coventry CV4 7AL, UK \\ ${ }^{4}$ Department of Physics, University of Guelph, 50 Stone Road East, Guelph, Ontario, Canada N1G \\ 2W1 \\ ${ }^{5}$ Francis Bitter Magnet Laboratory and Department of Chemistry, Massachusetts Institute of \\ Technology, Cambridge, Massachusetts 02139, USA
}

\begin{abstract}
A protocol is presented for correcting the effect of non-specific cross polarization in CHHC solidstate MAS NMR experiments, thus allowing the recovery of the ${ }^{1} \mathrm{H}_{-}{ }^{1} \mathrm{H}$ magnetization exchange functions from the mixing-time dependent buildup of experimental CHHC peak intensity. The presented protocol also incorporates a scaling procedure to take into account the effect of multiplicity of a $\mathrm{CH}_{2}$ or $\mathrm{CH}_{3}$ moiety. Experimental CHHC buildup curves are presented for $L$-Tyrosine. $\mathrm{HCl}$ samples where either all or only one in ten molecules are $\mathrm{U}_{-}{ }^{13} \mathrm{C}$ labeled. Good agreement between experiment and 11-spin SPINEVOLUTION simulation (including only isotropic ${ }^{1} \mathrm{H}$ chemical shifts) is demonstrated for the initial buildup ( $t_{\text {mix }}<100 \mu \mathrm{s}$ ) of CHHC peak intensity corresponding to an intramolecular close $(2.5 \AA) \mathrm{H}-\mathrm{H}$ proximity. Differences in the initial CHHC buildup are observed between the 1 in 10 dilute and $100 \%$ samples for cases where there is a close intermolecular $\mathrm{H}-\mathrm{H}$ proximity in addition to a close intramolecular $\mathrm{H}-\mathrm{H}$ proximity. For the dilute sample, $\mathrm{CHHC}$ cross peak intensities tended to significantly lower values for long mixing times (500 $\mu$ s) as compared to the $100 \%$ sample. This difference is explained as being due to the dependence of the limiting total magnetization on the ratio $N_{\text {obs }} / N_{\text {tot }}$ between the number of protons that are directly attached to ${ }^{1}{ }^{13} \mathrm{C}$ nucleus and hence contribute significantly to the observed ${ }^{13} \mathrm{C}$ CHHC NMR signal, and the total number of ${ }^{1} \mathrm{H}$ spins into the system. ${ }^{1} \mathrm{H}_{-}{ }^{1} \mathrm{H}$ magnetization exchange curves extracted from CHHC spectra for the $100 \% \mathrm{~L}$-Tyrosine. $\mathrm{HCl}$ sample exhibit a clear sensitivity to the root sum squared dipolar coupling, with fast build-up being observed for the shortest intramolecular distances $(2.5 \AA)$ and slower, yet observable build-up for the longer intermolecular distances (up to $5 \AA$ ).
\end{abstract}

*Corresponding Author, Fax.: ++40 264 420042, e-mail: cfilip@itim-cj.ro.

Publisher's Disclaimer: This is a PDF file of an unedited manuscript that has been accepted for publication. As a service to our customers we are providing this early version of the manuscript. The manuscript will undergo copyediting, typesetting, and review of the resulting proof before it is published in its final citable form. Please note that during the production process errors may be discovered which could affect the content, and all legal disclaimers that apply to the journal pertain. 


\section{Keywords}

Solid-State NMR; MAS; CHHC; ${ }^{1} \mathrm{H}-{ }^{1} \mathrm{H}$ dipolar coupling; distance constraints

\section{Introduction}

Solid-state nuclear magnetic resonance increasingly develops as an attractive tool for investigating complex molecular systems with practical relevance in biology, chemistry and materials science. For instance, structural investigations based on identifying protein intraresidue or neighboring residue ${ }^{13} \mathrm{C}-{ }^{13} \mathrm{C}\left({ }^{13} \mathrm{C}-{ }^{15} \mathrm{~N}\right)$ connectivities, distances, and angles are now almost routinely available from ${ }^{13} \mathrm{C}\left({ }^{15} \mathrm{~N}\right)$ solid-state NMR experiments optimized to work on multiply labeled samples [1-12], but constraints useful to elucidate the 3D structure of proteins [13], or to characterize supramolecular aggregates and crystal packing, are more difficult to obtain. A promising strategy for this purpose is to use the CHHC experiment [14-17], which makes use of the concept that such constraints are easier to extract using ${ }^{1} \mathrm{H}-{ }^{1} \mathrm{H}$ magnetization exchange, because protons are closer spaced in regions of interest (folding, or intermolecular contacts), and also more strongly dipolar coupled to each other than low $\gamma$ nuclei.

${ }^{1} \mathrm{H}-{ }^{1} \mathrm{H}$ magnetization exchange can be directly probed in a NOESY-type ${ }^{1} \mathrm{H}_{-}{ }^{1} \mathrm{H}$ spin-diffusion two-dimensional correlation experiment [18]. This has been shown for cases of small and moderately sized organic molecules, where sufficient ${ }^{1} \mathrm{H}$ resolution is obtained using fast MAS or homonuclear ${ }^{1} \mathrm{H}$ decoupling [19-24]. In a CHHC experiment (see pulse sequence in Figure 1), ${ }^{1} \mathrm{H}-{ }^{1} \mathrm{H}$ magnetization exchange is probed indirectly, taking advantage of the better resolution for the X nucleus. NHHC [17], NHHN [25] and PHHP [26] implementations as well as extensions to $3 \mathrm{D} \mathrm{C}(\mathrm{DQ}) \mathrm{C}(\mathrm{SQ}) \mathrm{HHC}$ and NHHCC experiments [10] have also been demonstrated. CHHC, NHHC and NHHN experiments are widely applied to biological systems such as microcrystalline proteins [10,17,27-32], fibrils [33-37], aggregates [38,39], chlorophylls [40-43], ion channels [44-46], RNA [47,48] and an anti-cancer agent [49], where cross peaks observed in spectra recorded with mixing times of typically at least $100 \mu \mathrm{s}$ are used as distance constraints for structure determination protocols.

The reliability of ${ }^{1} \mathrm{H}-{ }^{1} \mathrm{H}$ distance constraints determined from observed cross peaks in CHHCtype experiments has been demonstrated for small model compounds, e.g., amino acids [10, $15,17,25,28,50,51]$ as well as recently the microcrystalline $\mathrm{CrH}$ protein [30], where ${ }^{1} \mathrm{H}_{-}{ }^{1} \mathrm{H}$ distances are known from single-crystal diffraction data. Specifically, faster experimental buildup (as a function of the mixing time, $t_{\mathrm{mix}}$ ) of CHHC peak intensity is observed for shorter ${ }^{1} \mathrm{H}-{ }^{1} \mathrm{H}$ distances. Experimental $\mathrm{CHHC}$ buildup data has been analysed using a classical spin-diffusion model $[15,16]$, with the extracted spin diffusion coefficients allowing order-ofmagnitude estimates of ${ }^{1} \mathrm{H}^{1}{ }^{1} \mathrm{H}$ distances. Reif et al. [27] and Lange et al. [50] have shown that a good fit to experimental data is obtained using analytical expressions based on $n=0$ rotational resonance [52] and spectral spin diffusion [53,54], respectively. These expressions have a squared dependence on the dipolar coupling constant (and hence the internuclear distance) as well as a fitted phenomenological zero-quantum dephasing term, with the latter depending on the MAS frequency [50]. Elena et al. have presented a related treatment of direct ${ }^{1} \mathrm{H}_{-}{ }^{1} \mathrm{H}$ magnetization exchange using a multi-spin kinetic rate matrix approach that considers a sum of all relevant magnetization processes between sites $i$ and $j$ in different molecules in the crystal lattice $[22,23]$.

Advances in computing hardware and density-matrix simulation methodologies $[55,56]$ mean that the spin dynamics due to 10+ dipolar-coupled nuclei can be simulated. For example, the dephasing in ${ }^{13} \mathrm{C}$ free-induction decays and spin-echo experiments under rotor-synchronised Hahn-echo pulse trains have recently been simulated for 10 coupled spins $[57,58]$. In this 
paper, ${ }^{1} \mathrm{H}-{ }^{1} \mathrm{H}$ magnetization exchange is simulated for 11 -spin systems corresponding to specific proton-proton proximities in $L$-tyrosine. $\mathrm{HCl}$, for which experimental $\mathrm{CHHC}$ buildup data is presented. Specifically, a protocol is introduced to correct for non-specific crosspolarization (CP) and take into account $\mathrm{XH}_{\mathrm{n}}$ multiplicity, thus allowing a direct comparison between experimental and simulated data. The effect of inter- and intramolecular ${ }^{1} \mathrm{H}_{-}{ }^{1} \mathrm{H}$ proximities on ${ }^{1} \mathrm{H}^{1}{ }^{1} \mathrm{H}$ magnetization exchange is investigated using two $L$-tyrosine. $\mathrm{HCl}$ samples where either all or only one in ten molecules are $\mathrm{U}_{-}{ }^{13} \mathrm{C}$ labeled. For the all $\mathrm{U}_{-}{ }^{13} \mathrm{C}$ sample, differences in the rate of buildup of $\mathrm{CHHC}$ peak intensity are explained by considering the root sum squared dipolar couplings.

\section{Experimental details}

\subsection{Sample preparation}

$\mathrm{U}(98 \%)-{ }^{13} \mathrm{C}$ labeled $L$-Tyrosine was obtained from Cambridge Isotope Laboratories (Andover, MA, USA). Conversion to the $L$-Tyrosine $\cdot \mathrm{HCl}$ salt was achieved by dissolving $L$ tyrosine in $1 \mathrm{M} \mathrm{HCl}$, followed by freeze-drying using a vacuum-pump. Two samples were used in this study: $\mathrm{U}-{ }^{13} \mathrm{C} L$-Tyrosine. $\mathrm{HCl}$ refers to the sample as prepared above. A second sample was prepared by the recrystallization of the $\mathrm{U}_{-}{ }^{13} \mathrm{C}$ labeled $L$-Tyrosine with natural abundant $L$-Tyrosine in $1 \mathrm{M} \mathrm{HCl}$, so as to yield a $\mathrm{U}_{-}{ }^{13} \mathrm{C}^{\mathrm{dil}}{ }^{\mathrm{d}} 10 \% \mathrm{~L}$-Tyrosine. $\mathrm{HCl}$ sample, i.e., one in ten $L$-Tyrosine $\cdot \mathrm{HCl}$ molecules are fully ${ }^{13} \mathrm{C}$ labeled.

\subsection{NMR experiments}

Experiments were performed at room temperature on a Bruker AVANCE-400 spectrometer operating at a ${ }^{13} \mathrm{C}$ Larmor frequency of $100 \mathrm{MHz}$, at an MAS frequency of $10.5 \mathrm{kHz}$ using a Bruker $4 \mathrm{~mm}$ double-resonance probe.

In all experiments, $\mathrm{CP}$ transfer was optimized for the first Hartmann-Hahn matching condition $\left(v_{1 \mathrm{C}}=v_{1 \mathrm{H}}-v_{\mathrm{R}}\right)$, using ${ }^{1} \mathrm{H}$ and ${ }^{13} \mathrm{C} r f$ nutation frequencies of 51 and $40 \mathrm{kHz}$, respectively. For $\pi / 2{ }^{1} \mathrm{H} r f$ pulses, a $\pi / 2$ pulse length of $3.8 \mu$ s was used. During ${ }^{13} \mathrm{C}$ evolution periods, twopulse phase-modulated (TPPM) ${ }^{1} \mathrm{H}$ decoupling [59] was applied at a nutation frequency of 70 $\mathrm{kHz}\left(\Delta \phi=15^{\circ}\right.$ and pulse width of $\left.7.4 \mu \mathrm{s}\right)$. A recycle delay of $3 \mathrm{~s}$ was used.

The CHHC experiments were performed by using the pulse sequence depicted in Fig. 1, where the unwanted proton polarization left after the first $\mathrm{CP}$ contact pulse is removed by phasecycling the second $\pi / 2$ pulse on the ${ }^{1} \mathrm{H}$ channel, as introduced in ref. [40]. A contact pulse of $700 \mu$ s was used for the first CP, whereas a much shorter contact pulse- $(65 \mu \mathrm{s})$ was employed for the next two CP steps in order to favorize polarization transfer between bonded ${ }^{13} \mathrm{C}-{ }^{1} \mathrm{H}$ in $\mathrm{CH}$ and $\mathrm{CH}_{2}$ moieties. A $60 \mathrm{kHz}$ continuous wave decoupling field was also applied on the ${ }^{13} \mathrm{C}$ channel during the mixing time to reduce the negative effect of the ${ }^{13} \mathrm{C}^{-1} \mathrm{H}$ dipolar interaction upon the efficiency of ${ }^{1} \mathrm{H}-{ }^{1} \mathrm{H}$ polarization transfer. $256\left(\mathrm{U}_{-}{ }^{13} \mathrm{C}^{\mathrm{dil}}{ }^{10} 10 \%\right.$ sample) and $32\left(\mathrm{U}_{-}{ }^{13} \mathrm{C}\right.$ sample) transients were coadded for each of $256 t_{1}$ increments of $30 \mu \mathrm{s}$, corresponding to a $F_{1}$ spectral width of $16.6 \mathrm{kHz}$ which was chosen such as to fit only the six protonated ${ }^{13} \mathrm{C}$ resonances of interest. Sign discrimination in $t_{1}$ was achieved using the TPPI method. Total acquisition times for each 2D CHHC experiment were 54 hours and 7 hours for the $\mathrm{U}^{1}{ }^{13} \mathrm{C}^{\mathrm{dil}}{ }^{10 \%}$ and $\mathrm{U}_{-}{ }^{13} \mathrm{C}$ samples, respectively. The signal to noise ratio in the first row of the CHHC experiment for $t_{\mathrm{mix}}=0$ was better than $75: 1$ (U- ${ }^{13} \mathrm{C}^{\mathrm{dil}}{ }^{10 \%}$ ) and $120: 1$ (U- ${ }^{13} \mathrm{C}$ samples) for all centreband protonated ${ }^{13} \mathrm{C}$ resonances.

\subsection{Density matrix simulations}

Density-matrix simulations of ${ }^{1} \mathrm{H}-{ }^{1} \mathrm{H}$ magnetization exchange during the $t_{\text {mix }}$ period of a CHHC experiment were performed using the SPINEVOLUTION program [55] for $10 \mathrm{kHz}$ MAS and a ${ }^{1} \mathrm{H}$ Larmor frequency of $400 \mathrm{MHz}$. 11-spin systems based upon the proton 
coordinates as extracted from the crystal structure of $L$-Tyrosine $\cdot \mathrm{HCl}$ [60] were considered, using experimental ${ }^{1} \mathrm{H}$ isotropic chemical shift values (see the representative

SPINEVOLUTION input files in the Appendix). It was verified that the number of crystallite orientations used was sufficient to ensure convergence. ${ }^{1} \mathrm{H}$ CSAs were neglected - in separate simulations, it was found that small changes to the magnetization exchange curves only started to occur for CSA anisotropies in excess of $40 \mathrm{ppm}$ (for $L$ alanine, the largest calculated ${ }^{1} \mathrm{H}$ CSA has an anisotropy of $17 \mathrm{ppm}$ [58]). Each simulation directly provides the magnetizationexchange curves that correspond to the transfer from an initially polarized ${ }^{1} \mathrm{H}$ site, to the all chemically distinct proton sites in the system, and took approximately 120 hours on an Opteron Linux workstation.

\section{Theory}

\subsection{Magnetization exchange}

The transfer of $z$ magnetization between two dipolar coupled ${ }^{1} \mathrm{H}$ nuclei $j$ and $k$ during a mixing time, $t_{\text {mix }}$, under the spin-diffusion operator $\hat{U}$ is described here by a polarization transfer function, $F_{j k}\left(t_{m i x}\right)$ :

$$
F_{j k}\left(t_{\text {mix }}\right)=\left\langle I_{z}^{k}\left|\widehat{U}\left(t_{m i x}\right)\right| I_{z}^{j}\right\rangle
$$

In a CHHC experiment, a general ${ }^{13} \mathrm{C}_{-}{ }^{13} \mathrm{C}$ SQ-SQ correlation is established between ${ }^{13}{ }^{L}{ }^{L} \mathrm{H}_{p}$ and a ${ }^{13} \mathrm{C}^{M} \mathrm{H}_{q}$ resonance, via ${ }^{1} \mathrm{H}_{-}{ }^{1} \mathrm{H}$ magnetization exchange between $p{ }^{1} \mathrm{H}$ nuclei attached to ${ }^{13} \mathrm{C}^{L}$ and $q{ }^{1} \mathrm{H}$ nuclei attached to ${ }^{13} \mathrm{C}^{M}$. In such a case, it is convenient to define modified polarization transfer functions for the case of unlike and like spins, i.e., corresponding to off-diagonal and diagonal peaks in a 2D CHHC spectrum:

$$
\begin{gathered}
F_{L M}^{\prime}\left(t_{\text {mix }}\right)=\frac{1}{p q}\left\langle\sum_{k=1}^{q} I_{k z}^{M} \widehat{U}\left(t_{\text {mix }}\right) \mid \sum_{j=1}^{p} I_{j z}^{L}\right\rangle \\
F_{L L}^{\prime}\left(t_{\text {mix }}\right)=\frac{1}{p}\left\langle\sum_{j=1}^{p} I_{j z}^{L}\left|\widehat{U}\left(t_{\text {mix }}\right)\right| \sum_{j=1}^{p} I_{j z}^{L}\right\rangle
\end{gathered}
$$

The modified polarization transfer functions correspond to ${ }^{1} \mathrm{H}-{ }^{1} \mathrm{H}$ magnetization exchange starting from unit polarization on a given ${ }^{13} \mathrm{C}^{L} \mathrm{H}_{p}$ group. For $t_{\mathrm{mix}}=0, F_{L L}^{\prime}(0)=1$ and $F_{L M}^{\prime}(0)=0$.

In this paper, a normalized polarization transfer function is employed according to the definition:

$$
F_{L M}^{n}\left(t_{m i x}\right)=\frac{F_{L M}^{\prime}\left(t_{m i x}\right)}{F_{L L}^{\prime}(0)}
$$

\subsection{Compensating heteronuclear effects in $\mathrm{CHHC}$ experiments}

The indirect observation of ${ }^{1} \mathrm{H}-{ }^{1} \mathrm{H}$ magnetization exchange in a 2D CHHC experiment benefits from the considerably better ${ }^{13} \mathrm{C}$ as opposed to ${ }^{1} \mathrm{H}$ resolution. However, the two $\mathrm{CP}$ steps flanking the ${ }^{1} \mathrm{H}-{ }^{1} \mathrm{H}$ magnetization exchange period in the $\mathrm{CHHC}$ sequence are usually not fully 
specific even for the very short $\mathrm{CP}$ durations typically used $(<100 \mu \mathrm{s})$, i.e., magnetization is not transferred exclusively from a given ${ }^{13} \mathrm{C}$ nucleus to only its directly attached ${ }^{1} \mathrm{H}$ nucleus or nuclei, but rather magnetization "leaks out" onto other ${ }^{1} \mathrm{H}$ nuclei. As a consequence, the intensity of an experimental CHHC cross peak linking a ${ }^{13} \mathrm{C}^{L} \mathrm{H}_{p}$ and a ${ }^{13} \mathrm{C}^{M} \mathrm{H}_{q}$ resonance, $I_{L M}^{e x}\left(t_{\text {mix }}\right)$, does not correspond precisely to the ${ }^{1} \mathrm{H}-{ }^{1} \mathrm{H}$ polarization transfer functions described above. This section describes a procedure for recovering the ${ }^{1} \mathrm{H}-{ }^{1} \mathrm{H}$ polarization transfer functions from the experimental CHHC cross-peak intensities.

The intensity of an experimental CHHC cross peak linking a ${ }^{13} \mathrm{C}^{L} \mathrm{H}_{p}$ and a ${ }^{13} \mathrm{C}^{M} \mathrm{H}_{q}$ resonance, $I_{L M}^{e x}\left(t_{\text {mix }}\right)$, corresponds to:

$$
I_{L M}^{e x}\left(t_{m i x}\right)=a_{C P 1}^{L}\left\langle S_{x y}^{M}\left|\widehat{U}_{I S}\left(\tau_{C P}\right) \widehat{U}\left(t_{m i x}\right) \widehat{U}_{S I}\left(\tau_{C P}\right)\right| S_{x y}^{L}\right\rangle
$$

Note that $S$ and $I$ refer to ${ }^{13} \mathrm{C}$ and ${ }^{1} \mathrm{H}$ nuclei, respectively. The $a_{C P 1}^{L}$ coefficient takes into account the variation of initial (i.e., at the start of $\left.t_{1}\right){ }^{13} \mathrm{C}$ transverse magnetization for different ${ }^{13} \mathrm{C}$ resonances arising from the first $\mathrm{CP}$ step. The ${ }_{x y}$ subscript indicates spin $S$ transverse magnetization present at the end of $t_{1}$ or the start of $t_{2}$. The CP propagators in Eq. (5) are considered to include the contact pulse applied to both spin species and the ${ }^{1} \mathrm{H} 90^{\circ}$ pulse that creates $I_{z}\left({ }^{1} \mathrm{H}\right.$ population state) at the start of $t_{\text {mix }}$ or converts $I_{z}$ at the end of $t_{\text {mix }}$ into ${ }^{1} \mathrm{H}$ transverse magnetization before the final CP step, i.e., $\hat{U}_{S I}\left(\tau_{C P}\right)$ converts $S_{\mathrm{xy}}$ into $I_{\mathrm{Z}}$, while $\hat{U}_{I S}\left(\tau_{C P}\right)$ converts $I_{\mathrm{z}}$ into $S_{\mathrm{xy}}$. The CP dynamics can be described in terms of the transferred polarization:

$$
\widehat{U}_{S I}\left(\tau_{C P}\right)\left|S_{x y}^{L}\right\rangle \rightarrow \frac{\eta_{L}}{p}\left|\sum_{j=1}^{p} I_{j z}^{L}+\frac{\varepsilon_{L M}}{q}\right| \sum_{k=1}^{q} I_{k z}^{M}
$$

where the coefficient $\eta$ corresponds to the amount of magnetization transferred to proton(s) directly attached to the initial ${ }^{13} \mathrm{C}$ resonance, while the coefficient $\varepsilon$ corresponds to the amount of magnetization transferred to proton(s) attached to a different ${ }^{13} \mathrm{C}$ resonance. Similarly,

$$
\left\langle S_{x y}^{M}\right| \widehat{U}_{I S}\left(\tau_{C P}\right) \rightarrow\left\langle\sum_{k=1}^{q} I_{k z}^{M}\right| \frac{\eta_{M}}{q}+\left\langle\sum_{j=1}^{p} I_{j z}^{L}\right| \frac{\varepsilon_{M L}}{p}
$$

It thus follows that

$$
\begin{aligned}
& I_{L M}^{e x}\left(t_{m i x}\right)=a_{C P 1}^{L} \eta_{L} \eta_{M} \frac{\left\langle\sum_{k=1}^{q} I_{k z}^{M}\left|\widehat{U}\left(t_{m i x}\right)\right| \sum_{j=1}^{p} I_{j z}^{L}\right\rangle}{p q}+\frac{a_{C P 1}^{L} \eta_{M} \varepsilon_{L M}}{q} \frac{\left\langle\sum_{k=1}^{q} I_{k z}^{M} \widehat{U}\left(t_{m i x}\right) \mid \sum_{k=1}^{q} I_{k z}^{M}\right\rangle}{q} \\
& +\frac{a_{C P 1}^{L} \eta_{L} \varepsilon_{M L}}{p} \frac{\left\langle\sum_{j=1}^{p} I_{j=1}^{L} \widehat{U}\left(t_{m i x}\right) \mid \sum_{j=1}^{p} I_{j z}^{L}\right\rangle}{p}
\end{aligned}
$$

where the term in $\varepsilon_{L M} \varepsilon_{M L}$ has been neglected. 
The intensity of an experimental CHHC diagonal peak for a ${ }^{13} \mathrm{C}^{L} \mathrm{H}_{p}$ resonance, $I_{L L}^{e x}\left(t_{\text {mix }}\right)$, corresponds to:

$$
I_{L L}^{e x}\left(t_{m i x}\right)=a_{C P 1}^{L}\left\langle S_{x y}^{L}\left|\widehat{U}_{I S}\left(\tau_{C P}\right) \widehat{U}\left(t_{m i x}\right) \widehat{U}_{S I}\left(\tau_{C P}\right)\right| S_{x y}^{L}\right\rangle
$$

where

$$
\left\langle S_{x y}^{L}\right| \widehat{U}_{I S}\left(\tau_{C P}\right) \rightarrow\left\langle\sum_{j=1}^{p} I_{j z}^{L}\right| \frac{\eta_{L}}{p}+\left\langle\sum_{k=1}^{q} I_{k z}^{M}\right| \frac{\varepsilon_{L M}}{q}
$$

i.e.,

$I_{L L}^{e x}\left(t_{\text {mix }}\right)=\frac{a_{C P 1}^{L} \eta_{L}{ }^{2}}{p} \frac{\left\langle\sum_{j=1}^{p} I_{j z}^{L}\left|\widehat{U}\left(t_{\text {mix }}\right)\right| \sum_{j=1}^{p} I_{j z}^{L}\right\rangle}{p}+a_{C P 1}^{L} \eta_{L} \varepsilon_{L M} \frac{\left\langle\sum_{j=1}^{p} I_{j z}^{L}\left|\widehat{U}\left(t_{\text {mix }}\right)\right| \sum_{k=1}^{q} I_{k z}^{M}\right\rangle}{p q}$

$+a_{C P 1}^{L} \eta_{L} \varepsilon_{L M} \frac{\left\langle\sum_{k=1}^{p} I_{k z}^{M} \widehat{U}\left(t_{m i x}\right) \mid \sum_{j=1}^{p} I_{j z}^{L}\right\rangle}{p q}$

where the term in $\varepsilon_{L M}{ }^{2}$ has been neglected.

Using Eqs. (2) and (3), Eqs. (8) and (11) become:

$$
\begin{gathered}
I_{L M}^{e x}\left(t_{m i x}\right)=a_{C P 1}^{L}\left[\eta_{L} \eta_{M} F_{L M}^{\prime}\left(t_{m i x}\right)+\frac{\eta_{M} \varepsilon_{L M}}{q} F_{M M}^{\prime}\left(t_{m i x}\right)+\frac{\eta_{L} \varepsilon_{M L}}{p} F_{L L}^{\prime}\left(t_{m i x}\right)\right] \\
I_{L L}^{e x}\left(t_{m i x}\right)=a_{C P 1}^{L}\left[\frac{\eta_{L}^{2}}{p} F_{L L}^{\prime}\left(t_{\text {mix }}\right)+\eta_{L} \varepsilon_{L M} F_{M L}^{\prime}\left(t_{m i x}\right)+\eta_{L} \varepsilon_{L M} F_{L M}^{\prime}\left(t_{m i x}\right)\right]
\end{gathered}
$$

For a short $t_{m i x}, F_{M L}^{\prime}\left(t_{m i x}\right)$ and $F_{L M}^{\prime}\left(t_{m i x}\right)$ are both small, while for a short $\tau_{C P}, \varepsilon_{L M}$ and $\varepsilon_{M L}$ are also small. For such conditions, Eq. (13) simplifies to

$$
I_{L L}^{e x}\left(t_{\text {mix }}\right)=\frac{a_{C P 1}^{L} \eta_{L}^{2}}{p} F_{L L}^{\prime}\left(t_{\text {mix }}\right)
$$

i.e.,

$$
F_{L L}^{\prime}\left(t_{m i x}\right)=\frac{p}{a_{C P 1}^{L} \eta_{L}^{2}} I_{L L}^{e x}\left(t_{m i x}\right)
$$


Eq. (12) can, then, be reexpressed as

$$
\begin{aligned}
& I_{L M}^{e x}\left(t_{\text {mix }}\right)=a_{C P 1}^{L} \eta_{L} \eta_{M} F_{L M}^{\prime}\left(t_{\text {mix }}\right)+\frac{\eta_{M} \varepsilon_{L M}}{q} \frac{q}{\eta_{M}{ }^{2}} I_{M M}^{e x}\left(t_{\text {mix }}\right)+\frac{\eta_{L} \varepsilon_{M L}}{p} \frac{p}{\eta_{L}{ }^{2}} I_{L L}^{e x}\left(t_{\text {mix }}\right) \\
& =a_{C P 1}^{L} \eta_{L} \eta_{M} F_{L M}^{\prime}\left(t_{\text {mix }}\right)+\frac{\varepsilon_{L M}}{\eta_{M}} I_{M M}^{e x}\left(t_{\text {mix }}\right)+\frac{\varepsilon_{M L}}{\eta_{L}} I_{L L}^{e x}\left(t_{\text {mix }}\right)
\end{aligned}
$$

By analogy

$$
I_{M L}^{e x}\left(t_{m i x}\right)=a_{C P 1}^{M} \eta_{L} \eta_{M} F_{M L}^{\prime}\left(t_{m i x}\right)+\frac{\varepsilon_{M L}}{\eta_{L}} I_{L L}^{e x}\left(t_{m i x}\right)+\frac{\varepsilon_{L M}}{\eta_{M}} I_{M M}^{e x}\left(t_{m i x}\right)
$$

The differences between Eqs. (16) and (17) explain why L to $\mathrm{M}$ and $\mathrm{M}$ to $\mathrm{L}$ cross peaks in CHHC experiments can exhibit different intensities for non-zero $t_{\mathrm{mix}}$.

Rearranging Eq. (16),

$$
F_{L M}^{\prime}\left(t_{m i x}\right)=\frac{1}{a_{C P 1}^{L} \eta_{L} \eta_{M}}\left[I_{L M}^{e x}\left(t_{\text {mix }}\right)-\frac{\varepsilon_{L M}}{\eta_{M}} I_{M M}^{e x}\left(t_{m i x}\right)-\frac{\varepsilon_{M L}}{\eta_{L}} I_{L L}^{e x}\left(t_{\text {mix }}\right)\right]
$$

Using Eqs. (15) and (18), the normalized polarization transfer function defined in Eq. (4) is given as:

$F_{L M}^{n}\left(t_{\text {mix }}\right)=\frac{F_{L M}^{\prime}\left(t_{\text {mix }}\right)}{F_{L L}^{\prime}(0)}=f_{L M}\left(\frac{I_{L M}^{e x}\left(t_{\text {mix }}\right)-\frac{\varepsilon_{L M}}{\eta_{M}} I_{M M}^{e x}\left(t_{\text {mix }}\right)-\frac{\varepsilon_{M L}}{\eta_{L}} I_{L L}^{e x}\left(t_{\text {mix }}\right)}{I_{L L}^{e x}(0)}\right)$

where

$$
f_{L M}=\frac{\eta_{L}}{p \eta_{M}}
$$

Eq. (19) defines how the normalized polarization transfer functions - corresponding to only ${ }^{1} \mathrm{H}-{ }^{1} \mathrm{H}$ magnetization exchange, i.e., with no distorting effect from non-specific $\mathrm{CP}-$ can be extracted from the experimental CHHC cross peak intensities.

The following describes how the coefficients in Eq. (19) can be experimentally determined. Using the above theoretical model, it can be shown that the ratio $\beta_{L}$ of the intensity of a specific ${ }^{13} \mathrm{C}$ resonance recorded in a CHHC filtered spectrum (obtained by using the $\mathrm{CHHC}$ pulse sequence with $t_{1}$ and $t_{\text {mix }}$ set to zero), $a_{\text {CHнC }}^{L}$, and that acquired after the first CP step, $a_{C P 1}^{L}$, can be related to the corresponding CP transfer parameter, $\eta_{L}$, and proton multiplicity, through:

$$
\beta_{L}=\frac{a_{C H H C}^{L}}{a_{C P 1}^{L}}=\frac{\eta_{L}^{2}}{p}
$$


It then follows that

$$
\eta_{L}=\sqrt{p \beta_{L}}
$$

By inserting this in eq. (20) the following expression is obtained for the $f_{L M}$ coefficient

$$
f_{L M}=\frac{1}{\sqrt{p q}} \sqrt{\frac{\beta_{L}}{\beta_{M}}}
$$

which provides the desired dependence only on the experimentally measured parameters $\beta_{L(M)}$.

For $t_{\text {mix }}=0, F_{L M}^{\prime}\left(t_{\text {mix }}\right)=F_{M L}^{\prime}\left(t_{\text {mix }}\right)=0$, and hence Eq. (16) becomes

$$
I_{L M}^{e x}(0)=I_{M L}^{e x}(0)=\frac{\varepsilon_{M L}}{\eta_{L}} I_{L L}^{e x}(0)+\frac{\varepsilon_{L M}}{\eta_{M}} I_{M M}^{e x}(0)
$$

Within the approximation that $\varepsilon=\varepsilon_{L M}=\varepsilon_{M L} \varepsilon$ can be determined:

$$
\varepsilon_{L M}=\frac{I_{L M}^{e x}(0)}{\left[\frac{I_{L L}^{e x}(0)}{\eta_{L}}+\frac{I_{M M}^{e x}(0)}{\eta_{M}}\right]}
$$

where $\eta_{L}$ and $\eta_{M}$ are determined using Eq. (22).

The above calculation is for the case where all carbon nuclei are ${ }^{13} \mathrm{C}$, i.e., where all molecules are $\mathrm{U}^{13} \mathrm{C}$ labelled. For a dilute sample, which corresponds to the case where only a proportion $\rho$ of the molecules are $\mathrm{U}_{-}{ }^{13} \mathrm{C}$ labeled, it is necessary to correct for the contribution to the diagonal peak intensity of the natural abundance ${ }^{13} \mathrm{C}$ nuclei (denoted here as $\xi$, with $\xi=0.011$ for ${ }^{13} \mathrm{C}$ ) in the proportion $(1-\rho)$ of the molecules at natural abundance. This correction is required since only $\xi^{2}$ molecules will have two neighboring ${ }^{13} \mathrm{C}$-labeled atoms, so as to give rise to cross peak intensity $I_{L M}^{e x}(0)$, as compared to the $\xi$ molecules that have a single ${ }^{13} \mathrm{C}$-labeled atom that contributes to the diagonal peak intensity. Considering the diagonal peak intensity, $I_{L I}^{e x}(0)$, there is a contribution $\xi(1-\rho)$ from molecules at natural abundance in addition to the $\rho$ from the $\mathrm{U}^{13} \mathrm{C}$ labeled molecules. It is hence necessary to modify Eq. (25)

$$
\varepsilon_{L M}=\frac{I_{L M}^{e x}(0)}{\left\lfloor\frac{\lambda I_{L L}^{e x}(0)}{\eta_{L}}+\frac{\lambda I_{M M}^{e x}(0)}{\eta_{M}}\right]}
$$

where 


$$
\lambda=\frac{\rho}{\rho+\xi(1-\rho)}
$$

i.e., for ${ }^{13} \mathrm{C}, \lambda=0.91$ when $\rho=0.1$. Eq. (26) does not include a correction to the cross peak intensity $I_{I M}^{e x}(0)$ which is given by $\rho /\left[\rho+\xi^{2}(1-\rho)\right]$, since this equals 1.00 to two decimal places for ${ }^{13} \mathrm{C}$ when $\rho=0.1$.

For a dilute sample, it is also necessary to modify Eq. (19):

$F_{L M}^{n}\left(t_{\text {mix }}\right)=\frac{F_{L M}^{\prime}\left(t_{\text {mix }}\right)}{F_{L L}^{\prime}(0)}=f_{L M}\left(\frac{I_{L M}^{e x}\left(t_{\text {mix }}\right)-\frac{\varepsilon_{L M}}{\eta_{M}} \lambda I_{M M}^{e x}\left(t_{\text {mix }}\right)-\frac{\varepsilon_{M L}}{\eta_{L}} \lambda I_{L L}^{e x}\left(t_{\text {mix }}\right)}{\lambda I_{L L}^{e x}(0)}\right)$

\section{Results and Discussion}

\subsection{One-dimensional ${ }^{13} \mathrm{C}$ CP MAS and CHHC-filtered spectra}

Figure 2 compares ${ }^{13} \mathrm{C} \mathrm{CP}$ MAS (thin line) and ${ }^{13} \mathrm{C} \mathrm{CHHC}$-filtered $\left(t_{1}=t_{\text {mix }}=0, \tau_{\mathrm{CP}}=65 \mu \mathrm{s}\right.$ for the last two CP steps) spectra (thick line) for (a) $\mathrm{U}_{-}{ }^{13} \mathrm{C}$ and (b) $\mathrm{U}^{13} \mathrm{C}^{\mathrm{dil}}{ }^{10 \%} \mathrm{~L}$ -

Tyrosine $\mathrm{HCl}$. The $\eta_{\mathrm{L}} \mathrm{CP}$ transfer coefficients as determined from a comparison of the signal intensity in the CP MAS and CHHC-filtered experiments (see Eq. (22)) are listed in Table 1.

\subsection{Two-dimensional CHHC spectra}

Fig. 3 presents $2 \mathrm{D}$ CHHC $\left(\tau_{\mathrm{CP}}=65 \mu\right.$ f for the last two CP steps) spectra of $(\mathrm{a}, \mathrm{b}) \mathrm{U}_{-}{ }^{13} \mathrm{C}$ and (c,d) $\mathrm{U}^{13} \mathrm{C}^{\text {dil__10\% }} \mathrm{L}$-Tyrosine. $\mathrm{HCl}$ recorded with $t_{\text {mix }}$ equal to (a,c) 0 and (b,d) $100 \mu \mathrm{s}$. Fig. 4 presents rows through the $F_{1}$ resonances corresponding to the six protonated ${ }^{13} \mathrm{C}$ nuclei, as extracted from the $\mathrm{CHHC}$ spectra at zero mixing time. It is evident that non specific $\mathrm{CP}$ during the last two CP steps of the $\mathrm{CHHC}$ experiment gives rise to noticeable $\mathrm{CHHC}$ cross peaks between directly bonded ${ }^{13} \mathrm{C}$ nuclei (i.e., $2 \& 4,3 \& 5$, and $7 \& 8$ ), even for the case of zero mixing time. This is also evident in Fig. 5(a) and (b) which presents the buildup of $\mathrm{C} 7$ $\left({ }^{\beta} \mathrm{CH}_{2}\right)$ to $\mathrm{C} 8\left({ }^{\alpha} \mathrm{CH}\right)$ (open symbols) and $\mathrm{C} 8$ to $\mathrm{C} 7$ (filled symbols) cross-peak intensity as a function of $t_{\text {mix }}$ for (a) $\mathrm{U}_{-}{ }^{13} \mathrm{C}$ and (b) $\mathrm{U}_{-}{ }^{13} \mathrm{C}^{\text {dil__}}{ }^{10 \%} \mathrm{~L}$-Tyrosine.HCl. Specifically, the crosspeak intensities are normalized with respect to the intensity of the corresponding diagonal peak for zero mixing time, i.e., $I_{L M}^{e x}\left(t_{m i x}\right) / I_{L L}^{e x}(0)$ such that the $\mathrm{C} 7$ to $\mathrm{C} 8$ and $\mathrm{C} 8$ to $\mathrm{C} 7$ cross-peak intensities are divided by the intensity of the $\mathrm{C} 7$ and $\mathrm{C} 8$ diagonal peak intensity for zero mixing time, respectively. In the case of the $\mathrm{U}_{-}{ }^{13} \mathrm{C}^{\text {dil_1 }} 10 \%$ sample, a scaling by the factor $\lambda$ as defined in Eq. (27) of 0.91 was applied to $I_{L L}^{e x}(0)$.

Section 3.2 (see Eqs. (19) \& (28)) describes a procedure for recovering the ${ }^{1} \mathrm{H}-{ }^{1} \mathrm{H}$ magnetization exchange behavior given by $F_{L M}^{n}\left(t_{\text {mix }}\right)$ from the experimental CHHC buildup curves. Fig. 5(c) and (d) presents such corrected normalized buildup plots for the $\mathrm{C} 7$ to $\mathrm{C} 8$ and $\mathrm{C} 8$ to $\mathrm{C} 7$ cross peaks for (c) $\mathrm{U}_{-}{ }^{13} \mathrm{C}$ and (d) $\mathrm{U}_{-}{ }^{13} \mathrm{C}^{\mathrm{dil}} \mathrm{10 \%} \mathrm{L}$-Tyrosine. $\mathrm{HCl}$. In the evaluation of the $\varepsilon_{L M}$ coefficients (see Eqs. (25) \& (26)), the coefficient was set to zero when $I_{L M}^{e x}\left(t_{m i x}\right) / I_{L L}^{e x}(0)<0.01$, i.e., when a particular cross-peak was less than $1 \%$ of the intensity of the corresponding diagonal peak. The evaluated non-zero $\varepsilon_{L M}$ coefficients for the different CHHC cross peaks are listed in Table 2. Considering Fig. 5(c) and (d), it is evident that all corrected curves now start at zero. As shown below, this allows for a clear comparison with the ${ }^{1} \mathrm{H}-{ }^{1} \mathrm{H}$ magnetization exchange build-up behavior obtained from numerical density matrix simulations. The corrected experimental $\mathrm{C} 7$ to $\mathrm{C} 8$ and $\mathrm{C} 8$ to $\mathrm{C} 7$ transfer functions are observed to be the same within (or close to within) the experimental error bars. In the following, 
experimental $F_{L, M}^{n}\left(t_{m i x}\right)$ values for a $C^{L}, C^{M}$ pair are shown as an average of $F_{L M}^{n}\left(t_{m i x}\right)$ and $F_{M L}^{n}\left(t_{m i x}\right)$.

\subsection{Comparison of experimental and simulated $\mathrm{CHHC}$ build-up curves}

Corrected normalized buildup plots, i.e., $F_{L, M}^{n}\left(t_{m i x}\right)$, for $\mathrm{U}^{13}{ }^{13} \mathrm{C}$ (circles) and $\mathrm{U}_{-}{ }^{13} \mathrm{C}^{\text {dil_} \_10 \%}$ (triangles) $L$-Tyrosine $\cdot \mathrm{HCl}$ are shown in Fig. 6 for the (a) C7-C8 and (b) $\mathrm{C} 2-\mathrm{C} 4 \mathrm{CHHC}$ cross peaks. The experimental data is compared to a SPINEVOLUTION simulation (solid line) of the $F_{L M}^{n}\left(t_{m i x}\right)^{1} \mathrm{H}-{ }^{1} \mathrm{H}$ magnetization function defined in Eq. (4) for 11-spin systems centered around the $\mathrm{H} 7$ (two protons) \& $\mathrm{H} 8$ and $\mathrm{H} 2 \& \mathrm{H} 4{ }^{1} \mathrm{H}$ nuclei, as shown in Fig. 6(c) and (d). Interproton distances for the 11-spin systems are given in Tables 3 and 4 .

Comparing the experimental data in Fig. 6(a) and (b) with the simulated 11 -spin ${ }^{1} \mathrm{H}_{-}{ }^{1} \mathrm{H}$ magnetization exchange curves, while there is good agreement for short $t_{\text {mix }}(<100 \mu \mathrm{s})$, it is noticeable that the experimental data for the $\mathrm{U}_{-1}{ }^{13} \mathrm{C}^{\mathrm{dil}}{ }^{10 \%}$ sample, in particular, trends to a markedly lower value than that for the simulation at long mixing times. For the diluted sample, the unlabeled molecules located around a fully ${ }^{13} \mathrm{C}$-labeled molecule can be viewed as a proton bath where a significant amount of the initial polarization is lost, because it cannot be backtransferred to observable ${ }^{13} \mathrm{C}$ NMR signal during the last $\mathrm{CP}$ block. This is responsible for the much stronger attenuation of the CHHC cross-peak intensities at large mixing times in the $10 \%$-diluted sample compared to the $100 \%$ sample. Quantitatively, the efficiency loss by this mechanism is illustrated in Fig. 7. Specifically, Fig. 7 compares for the U- ${ }^{13} \mathrm{C}$ (circles) and $\mathrm{U}-{ }^{13} \mathrm{C}^{\text {dil_}} 10 \%$ (triangles) $L$-Tyrosine $\cdot \mathrm{HCl}$ samples the evolution with the mixing time of the total observable experimental polarization that originates from an initial unit $\mathrm{C} 7$ polarization. This is defined as the sum of the normalized $\mathrm{I}_{\mathrm{C} 7}$ diagonal peak intensity and the intensities $\mathrm{I}_{\mathrm{C} 7, \mathrm{C} j}$ within its associated cross-peak patterns (corrected by the procedure described above, i.e., $F_{L, M}^{n}\left(t_{m i x}\right)$ ), with $j=2,3,4,5$ and 8 . Considering that an equal distribution of ${ }^{1} \mathrm{H}$ polarization is obtained at large mixing times, and neglecting spin-lattice relaxation, an asymptotic evolution would be expected towards a saturation level given by the ratio $N_{\mathrm{obs}} / N_{\text {tot }}$ between the number of protons that are directly attached to a ${ }^{13} \mathrm{C}$ nucleus and hence contribute significantly to the observed ${ }^{13} \mathrm{C}$ NMR signal, and the total number of ${ }^{1} \mathrm{H}$ spins into the system. Its value is $N_{\text {obs }} / N_{\text {tot }}=7 / 12=0.58$ (NB: there are $7 \mathrm{CH}$ and $\mathrm{CH}_{2}$ protons and $5 \mathrm{NH}_{3}$ and $\mathrm{OH}$ protons in the L-Tyrosine $\cdot \mathrm{HCl}$ molecule) and $7 / 120=0.06$ in the case of the $\mathrm{U}_{-}{ }^{13} \mathrm{C}$ and U- ${ }^{13} \mathrm{C}^{\text {dil_}} 10 \%$ samples, respectively. As can be seen in Fig. 7 , the experimental total polarization trends towards these $N_{\mathrm{obs}} / N_{\text {tot }}$ values.

Considering the experimental data in Fig. 6(a) \& (b), differences are apparent for short mixing times $\left(t_{\text {mix }}<100 \mu \mathrm{s}\right)$ when comparing the buildup for the $\mathrm{U}_{-}{ }^{13} \mathrm{C}$ (circles) and $\mathrm{U}_{-}{ }^{13} \mathrm{C}^{\mathrm{dil}}{ }^{10 \%}$ (triangles) samples for (a) the $\mathrm{C} 7\left(\mathrm{CH}_{2}\right) \& \mathrm{C} 8\left({ }^{\alpha} \mathrm{CH}\right)$ and (b) the $\mathrm{C} 2$ and $\mathrm{C} 4$ (directly bonded aromatic carbons) CHHC cross peaks. Specifically, in Fig. 6(a), the observed buildup rate is faster for the $\mathrm{U}_{-}{ }^{13} \mathrm{C}$ sample, while in Fig. 6(b), the buildup is the same within the experimental noise for the $\mathrm{U}_{-}{ }^{13} \mathrm{C}$ and $\mathrm{U}_{-}{ }^{13} \mathrm{C}^{\mathrm{dil}}{ }^{10 \%}$ samples. This is a consequence of additional close intermolecular proximities for the $\mathrm{H} 7, \mathrm{H} 8$ case: the intra-and inter-molecular contributions to the total $\mathrm{C} 7, \mathrm{C} 8$ cross-peak buildup curve are of comparable magnitudes, as they correspond to H7-H8 inter-proton average distances of 2.8 and $3.2 \AA$, respectively (see Table 3 ). By comparison, for the $\mathrm{H} 2, \mathrm{H} 4$ case, the nearest intermolecular proximity is $4.5 \AA$ as compared to the intramolecular proximity of $2.5 \AA$ (see Table 4). The 11-spin SPINEVOLUTION simulations (solid line in Fig. 6(a) \& (b)) only consider intramolecular ${ }^{1} \mathrm{H}-{ }^{1} \mathrm{H}$ magnetization transfer - for $\mathrm{H} 7, \mathrm{H} 8$, see footnote ${ }^{\mathrm{d}}$ to Table 3 and the representative SPINEVOLUTION input files in the Appendix. Good agreement between experiment and simulation for short mixing times ( $<80 \mu \mathrm{s}$ ) is obtained for the $\mathrm{C} 7, \mathrm{C} 8$ buildup curve for the $\mathrm{U}_{-}{ }^{13} \mathrm{C}^{\mathrm{dil}}{ }^{10 \%}$ sample (triangles in Fig. 6(a)) and for the C2,C4 buildup curves in Fig. 6(b) for both samples, i.e., for those cases 
where intermolecular proximities do not contribute to the experimentally detected ${ }^{1} \mathrm{H}^{-}{ }^{1} \mathrm{H}$ magnetization exchange. The deviations between experiment and simulation at longer mixing times is a consequence of "loss" of magnetization experimentally to ${ }^{1} \mathrm{H}$ nuclei that are not bonded to a visible ${ }^{13} \mathrm{C}$ nucleus as discussed above (see Fig. 7).

\subsection{Analysis of the effect of multiple ${ }^{1} \mathrm{H}-{ }^{1} \mathrm{H}$ contacts in $\mathrm{CHHC}$ experiments}

Fig. 6 shows examples of ${ }^{1} \mathrm{H}$ magnetization exchange observed for two specific cases, namely an isolated single ${ }^{1} \mathrm{H}-{ }^{1} \mathrm{H}$ contact (H2,H4, Fig. 6(b)) and a relatively tight $\mathrm{H} 7-\mathrm{H} 8$ inter-molecular pair in the close neighborhood of a short intra-molecular H7-H8 pair (see Fig. 6(a) for the $\mathrm{U}^{13} \mathrm{C}$ sample). This section considers the ${ }^{1} \mathrm{H}$ magnetization exchange behavior for the different cases of ${ }^{1} \mathrm{H}-{ }^{1} \mathrm{H}$ contacts found in $L$-Tyrosine $\cdot \mathrm{HCl}$. Table 5 lists all ${ }^{1} \mathrm{H}_{-}{ }^{1} \mathrm{H}$ distances under $5 \AA$. If we define a "close" ${ }^{1} \mathrm{H}_{-}{ }^{1} \mathrm{H}$ contact as a distance under $3.5 \AA$, the ${ }^{1} \mathrm{H}_{-}{ }^{1} \mathrm{H}$ contacts corresponding to the distinct $\mathrm{CHHC}$ cross-peaks can be classified either with respect to the number of involved contacts, i.e., single- $(\mathrm{H} 2-\mathrm{H} 3, \mathrm{H} 2-\mathrm{H} 4, \mathrm{H} 2-\mathrm{H} 7, \mathrm{H} 3-\mathrm{H} 5, \mathrm{H} 3-\mathrm{H} 7, \mathrm{H} 4-\mathrm{H} 5$, $\mathrm{H} 4-\mathrm{H} 7, \mathrm{H} 5-\mathrm{H} 8)$, double- (H2-H5, H5-H7, H7-H8), and triple contacts (H3-H4), or according to their type, i.e., only intra- $(\mathrm{H} 2-\mathrm{H} 4, \mathrm{H} 3-\mathrm{H} 5, \mathrm{H} 4-\mathrm{H} 7, \mathrm{H} 5-\mathrm{H} 8)$, only inter- $(\mathrm{H} 2-\mathrm{H} 3, \mathrm{H} 2-\mathrm{H} 5$, $\mathrm{H} 2-\mathrm{H} 7, \mathrm{H} 3-\mathrm{H} 4, \mathrm{H} 3-\mathrm{H} 7, \mathrm{H} 4-\mathrm{H} 5)$, and mixed intra- and inter-molecular ${ }^{1}{ }^{-}{ }^{1}{ }^{1} \mathrm{H}$ contacts $(\mathrm{H} 5-$ $\mathrm{H} 7, \mathrm{H} 7-\mathrm{H} 8$ ). Note that for the case of $\mathrm{H} 7$ that corresponds to the two $\mathrm{CH}_{2}$ protons, proximities of the same type and from the same other proton to both $\mathrm{CH}_{2}{ }^{\mathrm{a}}$ and $\mathrm{CH}_{2}{ }^{\mathrm{b}}$ are only counted once in the above classification - this is consistent with proton multiplicity being explicitly taken into account in the above analysis (see section 3.1).

The simplest case corresponds to single ${ }^{1} \mathrm{H}-{ }^{1} \mathrm{H}$ intra-molecular contacts, i.e., $\mathrm{C} 2-\mathrm{C} 4, \mathrm{C} 3-\mathrm{C} 5$, C4-C7 and C5-C8. The example of the $\mathrm{C} 2-\mathrm{C} 4 \mathrm{CHHC}$ buildup curves (Fig. 6(b) has been discussed above: the observed good correspondence between the two experimental curves for the $\mathrm{U}_{-}{ }^{13} \mathrm{C}$ and $\mathrm{U}_{-}{ }^{13} \mathrm{C}^{\text {dil_}} 10 \%$ samples on the one hand, and between the experiment and simulation, on the other hand, are illustrative for the conditions that must satisfied by a short $2.5 \AA$ contact (i.e., corresponding to directly bonded $\mathrm{CH}_{n}$ moieties) that can be considered as a single contact. It is evident that the added contribution to magnetization exchange dynamics of the closest ${ }^{1} \mathrm{H}-{ }^{1} \mathrm{H}$ contacts can be safely neglected if they correspond to inter-proton distances larger than about $\sim 4 \AA$. The identification of such intramolecular single contacts is useful in that they provide (as discussed below) reference curves for the analysis of other buildup curves that depend on contributions from multiple contacts.

In the following, we consider experimental $\mathrm{CHHC}$ data for $\mathrm{U}-{ }^{13} \mathrm{C} L$-Tyrosine $\cdot \mathrm{HCl}$, where close intermolecular ${ }^{1} \mathrm{H}^{1}{ }^{1} \mathrm{H}$ proximities will affect the observed buildup curves. Specifically, Fig. 8 presents corrected normalized experimental CHHC buildup curves (corresponding to

$F_{L, M}^{n}\left(t_{\text {mix }}\right)$ as defined in Eq. (19)) for magnetization starting on (a) C2, (b) C3, (c) C5 and (d) $\mathrm{C} 8$. As noted above, the data associated with single ${ }^{1} \mathrm{H}-{ }^{1} \mathrm{H}$ intra-molecular contacts, i.e., $\mathrm{C} 2-$ $\mathrm{C} 4, \mathrm{C} 3-\mathrm{C} 5$ and $\mathrm{C} 5-\mathrm{C} 8$ constitute single-contact intramolecular reference curves: The $\mathrm{C} 2-\mathrm{C} 4$, C3-C5 and C5-C8 peaks correspond to ${ }^{1} \mathrm{H}-{ }^{1} \mathrm{H}$ distances of $2.48(\mathrm{H} 2-\mathrm{H} 4)$ and $2.47 \AA$ (H3-H5) between neighboring aromatic protons and $2.56 \AA$ (H5-H8) between an aromatic proton and the $\mathrm{C} \alpha$ proton. While all curves are converging to a similar plateau intensity at the longest experimental $t_{\text {mix }}$ of $0.5 \mathrm{~ms}$, differences in rate of buildup are clearly evident. Importantly, in agreement with the use of the CHHC experiment to identify structural constraints, it will be shown that the differences in buildup rate are directly related to the root-sum-square coupling, $d_{\mathrm{rss}}$, [61-63] for the corresponding ${ }^{1} \mathrm{H}-{ }^{1} \mathrm{H}$ proximities (listed in Table 5):

$$
d_{\mathrm{rSs}}=\sqrt{\sum d_{j k}^{2}}
$$

where the dipolar coupling constant, $d_{\mathrm{jk}}$, is defined: 


$$
d_{\mathrm{jk}}=\left(-\frac{\mu_{0}}{4 \pi} \frac{\gamma_{H}^{2} \hbar}{r_{j k}^{3}}\right) / 2 \pi
$$

The close resemblance between the $\mathrm{C} 2-\mathrm{Cj}$ and $\mathrm{C} 3-\mathrm{Cj}$ patterns in Fig. 8 reveals the presence of relatively similar proton environments around the $\mathrm{H} 2$ and $\mathrm{H} 3$ protons. In both cases, the upper limit is provided by the corresponding single-contact intramolecular reference curve (C2-C4 and C3-C5), while the lower limit is established by the contact with the H8 proton. The slower buildup of the $\mathrm{C} 2-\mathrm{C} 8$ and $\mathrm{C} 3-\mathrm{C} 8$ curves is consistent with the closest $\mathrm{H}-\mathrm{H}$ proximity being over $4 \AA$ (H2-H8: intermolecular 4.14 $\AA$, H3-H8: intramolecular $4.75 \AA$ ). The remaining CHHC curves in the $\mathrm{C} 2-\mathrm{Cj}$ and $\mathrm{C} 3-\mathrm{Cj}$ patterns are distributed within the two limiting curves. As a common feature, all of them are encoding significant (in some cases multiple) intermolecular contributions, since their fast buildup is inconsistent with the large intramolecular ${ }^{1} \mathrm{H}-{ }^{1} \mathrm{H}$ distances (> 4.5 $\AA$ ). The C2-C3/C3-C2 buildup curve, determined by a single $2.9 \AA$ intermolecular contact, is the only one that can be directly compared with the reference curve in terms of the encoded distances. Nevertheless, the difference between the C2-C7 and C3-C7 buildup curves is consistent with the difference in the corresponding average nearest proton-proton distances of 3.0 and $3.5 \AA$, respectively and $d_{\text {rss }}=10.1$ and $4.6 \mathrm{kHz}$, respectively.

It is informative to compare the examples of the $\mathrm{C} 2-\mathrm{C} 5$ and $\mathrm{C} 3-\mathrm{C} 4$ buildup curves that correspond to multiple intermolecular proximities under $3.5 \AA$ (H2-H5 $2.76 \& 3.19 \AA, d_{\text {rss }}=$ $6.9 \mathrm{kHz} ; \mathrm{H} 3-\mathrm{H} 42.84,3.20 \& 3.24 \AA$, $d_{\mathrm{rss}}=7.4 \mathrm{kHz}$ ) with the curves corresponding to single $\mathrm{H}-\mathrm{H}$ proximities, i.e., the two intramolecular $\mathrm{C} 2-\mathrm{C} 4$ and $\mathrm{C} 3-\mathrm{C} 5$ reference curves and the $\mathrm{C} 2-$ C3/C3-C2 single intermolecular contact, where the closest $\mathrm{H}-\mathrm{H}$ distances are $2.48 \AA$ (H2-H4), $2.47 \AA(\mathrm{H} 3-\mathrm{H} 5)$ and $2.95 \AA(\mathrm{H} 2-\mathrm{H} 3)$ and $d_{\mathrm{rss}}=8.2 \mathrm{kHz}(\mathrm{H} 2-\mathrm{H} 4), d_{\mathrm{rss}}=8.3 \mathrm{kHz}(\mathrm{H} 3-\mathrm{H} 5)$ and $d_{\text {rss }}=5.5 \mathrm{kHz}(\mathrm{H} 2-\mathrm{H} 3)$. The closeness of the $\mathrm{C} 3-\mathrm{C} 4$ and C3-C5 buildup curves is consistent with the similar $d_{\mathrm{rss}}$ values. The effect of multiple ${ }^{1} \mathrm{H}-{ }^{1} \mathrm{H}$ proximities leading to a faster buildup is evident when comparing the $\mathrm{C} 2-\mathrm{C} 5$ and $\mathrm{C} 3-\mathrm{C} 4$ curves on the one hand with the $\mathrm{C} 2-\mathrm{C} 3$ curve on the other hand.

A good correspondence between the experimental $\mathrm{CHHC}$ data and the corresponding structural parameters was found also for the $\mathrm{C} 5-\mathrm{Cj}$ and $\mathrm{C} 8-\mathrm{Cj}$ patterns in Fig. 8. Notably, $\mathrm{C} 5-\mathrm{Cj}$ is representative for a ${ }^{1} \mathrm{H}$ site tightly coupled to its surrounding protons. Together with the intramolecular reference curves (C5-C3, C5-C8), the other three curves in this pattern also encode short inter-molecular contacts, with ${ }^{1} \mathrm{H}-{ }^{1} \mathrm{H}$ distances between 2.8 and $3.1 \AA$ and similar $d_{\text {rss }}$ values (between 4.9 and $9.7 \mathrm{kHz}$ ). At the other extreme, the $\mathrm{C} 8-\mathrm{Cj}$ pattern corresponds to strong couplings of $\mathrm{H} 8$ only with intra-molecular protons, whereas all the inter-molecular contacts are larger than $4 \AA$. This is clearly evidenced by the measured buildup curves.

\subsection{Comparison of $\mathrm{CHHC}$ build-up data for $\mathrm{U}-{ }^{13} \mathrm{C}$ and $\mathrm{U}-{ }^{13} \mathrm{C}$ dil_ $10 \%$ samples}

Fig. 9 compares corrected normalized buildup plots, i.e., $F_{L, M}^{n}\left(t_{m i x}\right)$, for U- ${ }^{13} \mathrm{C}$ (circles) and $\mathrm{U}-{ }^{13} \mathrm{C}^{\text {dil_}} 10 \%$ (triangles) $L$-Tyrosine $\cdot \mathrm{HCl}$ for the cases where significant intensity (i.e., above the noise level) is observed for the $\mathrm{U}_{-}{ }^{13} \mathrm{C}^{\mathrm{dil}}{ }^{10 \%}$ sample. These cases (C2-C4, C3-C5, C4-C7, $\mathrm{C} 5-\mathrm{C} 7, \mathrm{C} 5-\mathrm{C} 8$ and $\mathrm{C} 7-\mathrm{C} 8$ ) all correspond to closest intramolecular $\mathrm{H}-\mathrm{H}$ proximities under 3 $\AA$, while for the other cases, the closest intramolecular $\mathrm{H}-\mathrm{H}$ proximity is over $4 \AA$. In this context, while Fig. 8 shows $\mathrm{CHHC}$ buildup curves for the $\mathrm{U}^{13} \mathrm{C}$ sample involving $\mathrm{C} 8$ that correspond to closest $\mathrm{H}-\mathrm{H}$ distances of over $4 \AA$, for the $\mathrm{U}_{-}{ }^{13} \mathrm{C}^{\mathrm{dil}}{ }^{10 \%}$ sample, it is to be remembered that much $\mathrm{CHHC}$ signal intensity is lost to invisible protons attached to ${ }^{12} \mathrm{C}$ nuclei at longer mixing times (see Fig. 7 and section 4.3). Comparing the buildup curves for the $\mathrm{U}^{13}{ }^{13}$ and $\mathrm{U}_{-}{ }^{13} \mathrm{C}^{\mathrm{dil}}{ }^{10 \%}$ samples in the short $t_{\mathrm{mix}}$ regime $(<80 \mu \mathrm{s})$, it is observed that four of 
them (C2-C4, C3-C5, C4-C7, and $\mathrm{C5}-\mathrm{C} 8)$ are quite similar in shape, while for the $\mathrm{C} 5-\mathrm{C} 7$ and $\mathrm{C} 7-\mathrm{C} 8$ cases, faster buildup is observed for the $\mathrm{U}_{-}{ }^{13} \mathrm{C}$ sample. As was discussed in section 4.3 when comparing the $\mathrm{CHHC}$ data for $\mathrm{C} 7-\mathrm{C} 8$ and $\mathrm{C} 2-\mathrm{C} 4$ (see Fig. 6), this difference is a consequence of additional close $\mathrm{H} 5-\mathrm{H} 7$ and $\mathrm{H} 7-\mathrm{H} 8$ intermolecular proximities.

\section{Discussion}

CHHC-type experiments are being increasingly applied to indirectly probe ${ }^{1} \mathrm{H}-{ }^{1} \mathrm{H}$ magnetization exchange and hence obtain structural constraints, in particular, for large biomolecules. This paper has presented a protocol for correcting the effect of non-specific cross polarization in CHHC experiments, thus allowing the recovery of the ${ }^{1} \mathrm{H}-{ }^{1} \mathrm{H}$ magnetization exchange functions from the mixing-time dependent buildup of experimental CHHC peak intensity. The presented protocol also incorporates a scaling procedure to take into account the effect of multiplicity of a $\mathrm{CH}_{2}$ or $\mathrm{CH}_{3}$ moiety. In this way, direct comparison can be made between experimentally determined ${ }^{1}{ }^{1}-{ }^{1} \mathrm{H}$ magnetization exchange functions and numerical density-matrix simulations, without the requirement for any phenomenological factors. For $L$-Tyrosine. $\mathrm{HCl}$, good agreement between experiment and 11-spin simulation (including only isotropic ${ }^{1} \mathrm{H}$ chemical shifts) is demonstrated for the specific case of initial buildup $\left(t_{\text {mix }}<100\right.$ $\mu \mathrm{s})$ of CHHC peak intensity corresponding to an intramolecular close $(2.5 \AA) \mathrm{H}-\mathrm{H}$ proximity. The derived corrections are not limited to the case of ${ }^{1} \mathrm{H}_{-}{ }^{1} \mathrm{H}$ magnetization exchange, i.e., to zero-quantum mixing schemes, but they are also valid to CHHC experiments employing homonuclear ${ }^{1} \mathrm{H}_{-}{ }^{1} \mathrm{H}$ recoupling schemes [17,50].

For small and moderately sized organic molecules such as $L$-Tyrosine.HCl, the experimentally observed buildup of CHHC peak intensity often corresponds to a ${ }^{1} \mathrm{H}-{ }^{1} \mathrm{H}$ magnetization exchange behaviour that depends on both intra- and intermolecular proximities. Indeed, it is to be noted that the multi-spin kinetic rate matrix analysis of directly observed ${ }^{1} \mathrm{H}-{ }^{1} \mathrm{H}$ magnetization exchange by Elena et al. exploits the dependence on intermolecular ${ }^{1} \mathrm{H}-{ }^{1} \mathrm{H}$ proximities to determine the three-dimensional packing of organic molecules in the crystal lattice [22,23]. In the CHHC experiment, intermolecular effects can be removed by working with dilute samples where a $\mathrm{U}^{13} \mathrm{C}$ labeled molecule is recrystallised with an excess of molecules at natural abundance. This approach has been employed in previous studies where distance constraints extracted from CHHC experiments have been used as constraints in the structural determination of the three-dimensional conformation of organic molecules [4951]. In this paper, experimental CHHC buildup curves were presented for $L$-Tyrosine. $\mathrm{HCl}$ samples where either all or only one in ten molecules are $\mathrm{U}^{13} \mathrm{C}$ labeled. For the dilute sample, CHHC cross peak intensities tended to significantly lower values for long mixing times (500 $\mu \mathrm{s})$ than for the $100 \%$ sample. This difference has been explained here as being due to the dependence of the limiting total magnetization on the ratio $N_{\mathrm{obs}} / N_{\text {tot }}$ between the number of protons that are directly attached to a ${ }^{13} \mathrm{C}$ nucleus and hence contribute significantly to the observed ${ }^{13} \mathrm{C}$ CHHC NMR signal, and the total number of ${ }^{1} \mathrm{H}$ spins into the system.

It has been shown that insight into ${ }^{1} \mathrm{H}-{ }^{1} \mathrm{H}$ magnetization exchange under multiple intra- and intermolecular ${ }^{1} \mathrm{H}-{ }^{1} \mathrm{H}$ dipolar couplings can be obtained by a consideration of the root sum squared dipolar couplings corresponding to specific CHHC cross peaks. (Note that a sum squared dipolar coupling is also inherent to the multi-spin kinetic rate matrix analysis of directly observed ${ }^{1} \mathrm{H}-{ }^{1} \mathrm{H}$ magnetization exchange by Elena et al. [22,23]) ${ }^{1} \mathrm{H}-{ }^{1} \mathrm{H}$ magnetization exchange curves extracted from CHHC spectra for the $100 \% \mathrm{~L}$-Tyrosine. $\mathrm{HCl}$ sample exhibit a clear sensitivity to the root sum squared dipolar coupling, with fast build-up being observed for the shortest intramolecular distances $(2.5 \AA)$ and slower, yet observable build-up for the longer intermolecular distances (up to $5 \AA$ ). As is to be expected, differences in the initial CHHC buildup were observed between the 1 in 10 dilute and $100 \%$ samples for cases where there is a close intermolecular $\mathrm{H}-\mathrm{H}$ proximity in addition to a close intramolecular $\mathrm{H}-\mathrm{H}$ 
proximity. The demonstrated usefulness of the CHHC experiment as a valuable and reliable source of quantitative $\mathrm{H}-\mathrm{H}$ proximity information is consistent with previous studies of other small organic molecules [50,51] as well the microcrystalline $\mathrm{CrH}$ protein [30], for which ${ }^{1} \mathrm{H}-{ }^{1} \mathrm{H}$ distances are known from single-crystal diffraction data.

Of much current interest is the application of CHHC-type experiments, including the recently developed J-CHHC [64], to large biomolecules, where extracted ${ }^{1} \mathrm{H}_{-}{ }^{1} \mathrm{H}$ distances are then used as constraints in structural determination protocols [29,31,32,36,37,44,46,64]. For large biomolecules, the ${ }^{1} \mathrm{H}-{ }^{1} \mathrm{H}$ magnetization exchange as encoded in CHHC-type peaks is less complex than in the case of small and moderately sized molecules since intermolecular ${ }^{1} \mathrm{H}_{-}{ }^{1} \mathrm{H}$ proximities do not usually contribute, although $\mathrm{NHHC}$ experiments have been used to probe inter monomer contacts for the $\mathrm{CrH}$ microcrystalline protein [30]. As noted above, it has been shown here that good agreement between experiment and 11-spin simulation (including only isotropic ${ }^{1} \mathrm{H}$ chemical shifts) was observed for the initial buildup $\left(t_{\text {mix }}<100\right.$ $\mu \mathrm{s})$ of $\mathrm{CHHC}$ peak intensity corresponding to a single intramolecular H-H proximity. For large biomolecules, most CHHC-type peaks usually correspond to such single intramolecular $\mathrm{H}-\mathrm{H}$ proximities, thus suggesting that an analysis of CHHC-type buildup curves (using the protocol presented here to correct for non-specific $\mathrm{CP}$ and take into account $\mathrm{XH}_{\mathrm{n}}$ multiplicity) using multi-spin simulations could be utilised to check and refine $\mathrm{H}-\mathrm{H}$ distances in as-determined biomolecular structures.

\section{Acknowledgments}

Financial support from the ANCS, EPSRC, and the Royal Society is gratefully acknowledged. Tim Smith and Andrew Marsh (Warwick) are thanked for assistance with sample preparation.

\section{References}

1. Pauli J, Baldus M, Van Rossum B, De Groot H, Oschkinat H. Backbone and side-chain ${ }^{13} \mathrm{C}$ and ${ }^{15} \mathrm{~N}$ signal assignments of the $\alpha$-spectrin SH3 domain by magic angle spinning solid-state NMR at 17.6 Tesla. ChemBioChem 2001;2:272-281. [PubMed: 11828455]

2. Hohwy M, Rienstra CM, Griffin RG. Band-selective homonuclear dipolar recoupling in rotating solids. J Chem Phys 2002;117:4973-4987.

3. Jaroniec CP, Filip C, Griffin RG. 3D TEDOR NMR experiments for the simultaneous measurement of multiple carbon-nitrogen distances in uniformly ${ }^{13} \mathrm{C},{ }^{15} \mathrm{~N}$-labeled solids. J Am Chem Soc 2002;124:10728-10742. [PubMed: 12207528]

4. Petkova AT, Baldus M, Belenky M, Hong M, Griffin RG, Herzfeld J. Backbone and side chain assignment strategies for multiply labeled membrane peptides and proteins in the solid state. J Magn Reson 2003;160:1-12. [PubMed: 12565042]

5. Ladizhansky V, Jaroniec CP, Diehl A, Oschkinat H, Griffin RG. Measurement of multiple $\psi$ torsion angles in uniformly ${ }^{13} \mathrm{C}$, ${ }^{15} \mathrm{~N}$-labeled $\alpha$-spectrin SH3 domain using $3 \mathrm{D}{ }^{15} \mathrm{~N}-{ }^{13} \mathrm{C}--{ }^{13} \mathrm{C}-{ }^{15} \mathrm{~N}$ MAS dipolar-chemical shift correlation spectroscopy. J Am Chem Soc 2003;125:6827-6833. [PubMed: 12769594]

6. Williamson PTF, Verhoeven A, Ernst M, Meier BH. Determination of internuclear distances in uniformly labeled molecules by rotational-resonance solid-state NMR. J Am Chem Soc 2003;125:2718-2722. [PubMed: 12603160]

7. Ladizhansky V, Griffin RG. Band-Selective Carbonyl to Aliphatic Side Chain ${ }^{13} \mathrm{C}-{ }^{13} \mathrm{C}$ Distance Measurements in U- ${ }^{13} \mathrm{C},{ }^{15} \mathrm{~N}$-Labeled Solid Peptides by Magic Angle Spinning NMR. J Am Chem Soc 2004;126:948-958. [PubMed: 14733572]

8. Jaroniec CP, MacPhee CE, Bajaj VS, McMahon MT, Dobson CM, Griffin RG. High-resolution molecular structure of a peptide in an amyloid fibril determined by magic angle spinning NMR spectroscopy. PNAS 2004;101:711-716. [PubMed: 14715898]

9. Seidel K, Lange A, Becker S, Hughes CE, Heise H, Baldus M. Protein solid-state NMR resonance assignments from $\left({ }^{13} \mathrm{C},{ }^{13} \mathrm{C}\right)$ correlation spectroscopy. PCCP 2004;6:5090-5093. 
10. Heise H, Seidel K, Etzkorn M, Becker S, Baldus M. 3D NMR spectroscopy for resonance assignment and structure elucidation of proteins under MAS: Novel pulse schemes and sensitivity considerations. J Magn Reson 2005;173:64-74. [PubMed: 15705514]

11. Siemer AB, Ritter C, Steinmetz MO, Ernst M, Riek R, Meier BH. ${ }^{13} \mathrm{C},{ }^{15} \mathrm{~N}$ Resonance assignment of parts of the HET-s prion protein in its amyloid form. J Biomol NMR 2006;35:75-87. [PubMed: 16518695]

12. Grommek A, Meier BH, Ernst M. Distance information from proton-driven spin diffusion under MAS. Chem Phys Lett 2006;427:404-409.

13. Castellani F, Van Rossum B, Diehl A, Schubert M, Rehbein K, Oschkinat H. Structure of a Protein Determined by Solid-State Magic-Angle-Spinning NMR Spectroscopy. Nature 2002;420:98-102. [PubMed: 12422222]

14. Zhang S, Meier BH, Ernst RR. Polarization Echoes in NMR. Phys Rev Lett 1992;69:2149-2151. [PubMed: 10046411]

15. Wilhelm M, Feng H, Tracht U, Spiess HW. 2D CP/MAS ${ }^{13}$ C Isotropic Chemical Shift Correlation Established by ${ }^{1} \mathrm{H}$ Spin Diffusion. J Magn Reson 1998;134:255-260. [PubMed: 9761701]

16. Mulder FM, Heinen W, van Duin M, Lugtenburg J, de Groot HJM. Spin Diffusion with ${ }^{13}$ C Selection and Detection for the Characterization of Morphology in Labeled Polymer Blends with MAS NMR. J Am Chem Soc 1998;120:12891-12894.

17. Lange A, Luca S, Baldus M. Structural Constraints from Proton-Mediated Rare Spin Correlation Spectroscopy in Rotating Solids. J Am Chem Soc 2002;124:9704-9705. [PubMed: 12175218]

18. Caravatti P, Neuenschwander P, Ernst RR. Characterization of Heterogeneous Polymer Blends by Two-Dimensional Proton Spin Diffusion Spectroscopy. Macromolecules 1985;18:119-122.

19. Babonneau F, Gualandris V, Maquet J, Massiot D, Janicke MT, Chmelka BF. Newly Applied TwoDimensional Solid-State NMR Correlation Techniques for the Characterization of Organically Modified Silicates. J Sol-Gel Sci Technol 2000;19:113-117.

20. Goward GR, Schuster MFH, Sebastiani D, Schnell I, Spiess HW. High-resolution solid-state NMR studies of imidazole-based proton conductors: structure motifs and chemical exchange. J Phys Chem B 2002;106:9322-9334.

21. Brus J, Petrickova H, Dybal J. Influence of Local Molecular Motions on the Determination of ${ }^{1} \mathrm{H}-{ }^{1} \mathrm{H}$ Internuclear Distances Measured by 2D 1H Spin-Exchange Experiments. Solid State Nucl Magn Reson 2003;23:183-197. [PubMed: 12787902]

22. Elena B, Emsley L. Powder Crystalograpy by Proton Solid-State NMR Spectroscopy. J Am Chem Soc 2005;127:9140-9146. [PubMed: 15969592]

23. Elena B, Pintacuda G, Mifsud N, Emsley L. Molecular Structure Determination in Powders by NMR Crystallography from Proton Spin Diffusion. J Am Chem Soc 2006;128:9555-9560. [PubMed: 16848494]

24. Brown SP. Probing proton-proton proximities in the solid state. Progr Nucl Magn Reson Spectroscopy 2007;50:199-251.

25. Wei Y, Ramamoorthy A. 2D ${ }^{15} \mathrm{~N}-{ }^{15} \mathrm{~N}$ isotropic chemical shift correlation established by ${ }^{1} \mathrm{H}-{ }^{1} \mathrm{H}$ dipolar coherence transfer in biological solids. Chem Phys Lett 2001;342:312-316.

26. Massiot D, Alonso B, Fayon F, Fredoueil F, Bujoli B. New NMR developments for structural investogations of proton-bearing materials at different length scales. Sol St Sci 2001;3:11-16.

27. Reif B, van Rossum BJ, Castellani F, Rehbein K, Diehl A, Oschkinat H. Characterization of ${ }^{1} \mathrm{H}_{-}{ }^{1} \mathrm{H}$ distances in a uniformly ${ }^{2} \mathrm{H},{ }^{15} \mathrm{~N}$-labeled SH3 domain by MAS solid-state NMR spectroscopy. J Am Chem Soc 2003;125:1488-1489. [PubMed: 12568603]

28. Etzkorn M, Böckmann A, Lange A, Baldus M. Probing Molecular Interfaces Using 2D Magic-AngleSpinning NMR on Protein Mixtures with Different Uniform Labeling. J Am Chem Soc 2004;126:14746-14751. [PubMed: 15535698]

29. Seidel K, Etzkorn M, Heise H, Becker S, Baldus M. High-Resolution Solid-State NMR Studies on $\mathrm{U}\left[{ }^{13} \mathrm{C},{ }^{15} \mathrm{~N}\right]$-Labeled Ubiquitin. ChemBioChem 2005;6:1638-1647. [PubMed: 16094694]

30. Gardiennet C, Loquet A, Etzkorn M, Heise H, Baldus M, Bockmann A. Structural constraints for the Crh protein from solid-state NMR experiments. J Biomol NMR 2008;40:239-250. [PubMed: 18320329] 
31. Loquet A, Bardiaux B, Garninnet C, Blanchet C, Baldus M, Nilges M, Maliavin T, Bockmann A. 3D structure determination of the Crh protein from highly ambiguous solid-state NMR restraints. J Am Chem Soc 2008;130:3579-3589. [PubMed: 18284240]

32. Franks WT, Wylie BJ, Frericks Schmidt HL, Nieuwkoop AJ, Mayrhofer RM, Shah GJ, Graesser DT, Rienstra CM. Dipole tensor-based atomic-resolution structure determination of a nanocrystalline protein by solid-state NMR. PNAS 2008;105:4621-4626. [PubMed: 18344321]

33. Tycko R, Ishii Y. Constraints on Supramolecular Structure in Amyloid Fibrils from Two-Dimensional Solid-State NMR Spectroscopy with Uniform Isotopic Labelling. J Am Chem Soc 2003;125:66066607. [PubMed: 12769550]

34. Petkova AT, Buntkowsky G, Dyda F, Leapman RD, Yau WM, Tycko R. Solid State NMR Reveals a pH-dependent Antiparallel $\beta$-Sheet Registry in Fibrils Formed by a $\beta$-Amyloid Peptide. J Mol Biol 2004;335:247-260. [PubMed: 14659754]

35. Heise H, Hoyer W, Becker S, Andronesi OC, Riedel D, Baldus M. Molecular-level secondary structure, polymorphism, and dynamics of full-length of $\alpha$-synuclein fibrils studied by solid-sate NMR. PNAS 2005;102:15871-15876. [PubMed: 16247008]

36. Iwata K, Fujiwara T, Matsuki Y, Akutsu H, Takahashi S, Naiki H, Goto Y. 3D structure of amyloid protofilaments of beta2 micro-globulin fragment probed by solid-state NMR. PNAS 2006;103:18119-18124. [PubMed: 17108084]

37. Wasmer C, Lange A, Van Melckebeke H, Siemer AB, Riek R, Meier BH. Amyloid fibrils of the HET$\mathrm{s}(218-289)$ prion form a $\beta$ solenoid with a triangular hydrophobic core. Science 2008;319:15231526. [PubMed: 18339938]

38. Tang M, Waring AJ, Hong M. Intermolecular Packing and Alignment in an Ordered $\beta$-Hairpin Antimicrobial Peptide Aggregate from 2D Solid State NMR. J Am Chem Soc 2005; 127:1391913927. [PubMed: 16201813]

39. Andronesi OC, Von Bergen M, Biernat J, Seidel K, Griesinger C, Mandelkow E, Baldus M. Characterization of Alzheimer's-like paired helical filaments from the core domain of Tau protein using solid-state NMR spectroscopy. J Am Chem Soc 2008;130:5922-5928. [PubMed: 18386894]

40. de Boer I, Bosman L, Raap J, Oschkinat H, de Groot HJM. $2 \mathrm{D}{ }^{13} \mathrm{C}-{ }^{13} \mathrm{C}$ MAS NMR Correlation Spectroscopy with Mixing by True ${ }^{1} \mathrm{H}$ Spin Diffusion Reveals Long-Range Intermolecular Distance Restraints in Ultra High Magnetic Field. J Magn Reson 2002;157:286-291. [PubMed: 12323147]

41. de Boer I, Matysik J, Amakawa M, Yagai S, Tamiaki H, Holzwarth AR, de Groot HJM. MAS NMR Structures of a Microcrystalline Cd-Bacteriochlorophyll d-Analog. J Am Chem Soc 2003;125:13374-13375. [PubMed: 14583030]

42. de Boer I, Matysik J, Erkelens K, Sasaki S, Miyatake T, Yagai S, Tamiaki H, Holzwarth AR, de Groot HJM. MAS NMR Structures of Aggregated Cadmium Chlorins Reveal Molecular Control of SelfAssembly of Chlorosomal Bacteriochlorophylls. J Phys Chem B 2004;108:16566.

43. Ganapathy S, van Gammeren AJ, Hulsbergen FB, de Groot HJM. Probing Secondary, Tertiary, and Quaternary Structure along with Protein-Cofactor Interactions for a Helical Transmembrane Protein Complex through ${ }^{1} \mathrm{H}$ Spin Diffusion with MAS NMR Spectroscopy. J Am Chem Soc 2007;129:1504-1505. [PubMed: 17283988]

44. Lange A, Becker S, Seidel K, Giller K, Pongs O, Baldus M. A Concept for Rapid Protein-Structure Determination by Solid-State NMR Spectroscopy. Angew Chem Int Ed 2005;44:2089-2092.

45. Luo W, Yao X, Hong M. Large Structure Rearrangement of Colicin Ia Channel Domain after Membrane Binding from 2D ${ }^{13}$ C Spin Diffusion NMR. J Am Chem Soc 2005;127:6402-6408. [PubMed: 15853348]

46. Lange A, Giller K, Hornig S, Martin-Eauclaire MF, Pongs O, Becker S, Baldus M. Toxin-induced conformational changes in a potassium channel revealed by solid-state NMR. Nature 2006;440:959962. [PubMed: 16612389]

47. Riedel K, Leppert J, Ohlenschlager O, Gorlach M, Ramachandran R. Characterisation of hydrogen bonding networks in RNAs via magic angle spinning solid state NMR. J Biomol NMR 2005;31:331336. [PubMed: 15928999]

48. Riedel K, Herbst C, Hafner S, Leppert J, Ohlenschläger O, Swanson MS, Görlach M, Ramachandran R. Constraints on the Structure of (CUG) 97 RNA from Magic-Angle-Spinning Solid-State NMR Spectroscopy. Angew Chem Int Ed 2006;45:5620-5623. 
49. Lange A, Schupp T, Petersen F, Carlomagno T, Baldus M. High-Resolution Solid-State NMR Structure of an Anticancer Agent. ChemMedChem 2007;2:522-527. [PubMed: 17315255]

50. Lange A, Luca S, Baldus M. Analysis of Proton-Proton Transfer Dynamics in Rotating Solids and Their Use for 3D Structure Determination. J Am Chem Soc 2003;125:126410-12648.

51. Seidel K, Etzkorn M, Sonnenberg L, Griesinger C, Sebald A, Baldus M. Studying Molecular 3D Structure and Dynamics by High-Resolution Solid-State NMR: Application to L-TyrosineEthylester. J Phys Chem A 2005;109:2436-2442. [PubMed: 16833543]

52. Levitt MH, Raleigh DP, Creuzet F, Griffin RG. Theory and simulations of homonuclear spin pair systems in rotating solids. J Chem Phys 1990;92:6347.

53. Suter D, Ernst RR. Spin diffusion in resolved solid-state NMR spectra. Phys Rev B 1985;32:56085627.

54. Kubo A, McDowell CA. Spectral spin-diffusion in polycrystalline solids under magic-angle spinning. J Chem Soc Faraday Trans 1988;84:3713-3730.

55. Veshtort M, Griffin RG. SPINEVOLUTION: A powerful tool for the simulation of solid and liquid state NMR experiments. J Magn Reson 2006;178:248-282. [PubMed: 16338152]

56. Zorin V, Ernst M, Brown SP, Hodgkinson P. Insights into homonuclear decoupling from efficient numerical simulation: techniques and examples. J Mag Res 2008;192:183-196.

57. Filip X, Tripon C, Filip C. Heteronuclear Decoupling under Fast MAS by a Rotor-Syncronized HahnEcho Pulse Train. J Mag Res 2005;176:239-243.

58. Griffin JM, Tripon C, Samoson A, Filip C, Brown SP. Low-Load Rotor-Synchronized Hahn-Echo Pulse Train (RS-HEPT) ${ }^{1}$ H Decoupling in Solid-State NMR: Factors Affecting MAS Spin-Echo Dephasing Time. Magn Reson Chem 2007;45:S198-S208. [PubMed: 18098353]

59. Bennett AE, Rienstra CM, Auger M, Lakhsmi KV, Griffin RG. Heteronuclear Decoupling in Rotating Solids. J Chem Phys 1995;123:6951-6958.

60. Frey MN, Koetzle TF, Lehmann MS, Hamilton WC. Precision neutron diffraction structure determination of protein and nucleic acid components. X. A comparison between the crystal and molecular structures of L-tyrosine and L-tyrosine hydrochloride. J Chem Phys 1973;58:2547-2556.

61. Filip C, Hafner S, Schnell I, Demco DE, Spiess HW. Solid-state nuclear magnetic resonance spectra of dipolar-coupled multi-spin system under magic angle spinning. J Chem Phys 1999;110:423-440.

62. Zorin VE, Brown SP, Hodgkinson P. Quantification of homonuclear dipolar coupling networks from magic-angle spinning ${ }^{1} \mathrm{H}$ NMR. Mol Phys 2006;104:293-304.

63. Zorin VE, Brown SP, Hodgkinson P. Origins of linewidth in ${ }^{1} \mathrm{H}$ magic-angle spinning NMR. J Chem Phys 2006;125:144508. [PubMed: 17042610]

64. Loquet A, Laage S, Gardiennet C, Elena B, Emsley L, Böckmann A, Lesage A. Methyl proton contacts obtained using heteronuclear through-bond transfers in solid-state NMR spectroscopy. J Am Chem Soc 2008;130:10625-10632. [PubMed: 18630872]

\section{Appendix}

Representative SPINEVOLUTION input files used for the numerical simulation of the $F_{j k}$ $\left(t_{m i x}\right)$ polarization transfer functions in Eq. (1).

******* The System $* * * * * * * * * * * * * * * * * * * * * * * * * * * * * * * * * * *$

spectrometer $(\mathrm{MHz}) 400$

spinning_freq $(\mathrm{kHz}) 10$

channels H1

nuclei H1 H1 H1 H1 H1 H1 H1 H1 H1 H1 H1

atomic_coords cross87_d.cor 
cs_isotropic $32.84 .588877773 \mathrm{ppm}$

csa_parameters *

j_coupling *

quadrupole *

dip_switchboard *

csa_switchboard *

exchange_nuclei (4 5 6)

bond_len_nuclei $*$

bond_ang_nuclei *

tors_ang_nuclei $*$

groups_nuclei *

$* * * * * * *$ Pulse Sequence $* * * * * * * * * * * * * * * * * * * * * * * * * * * * * *$

\section{CHN 1}

timing (usec) (5) 200

power $(\mathrm{kHz}) 0$

phase (deg) 0

freq_offs $(\mathrm{kHz}) 0$

phase_cycling $* *(\mathrm{RCV})$

$* * * * * * * * * * * * * * * * * * * * * * * * * * * \mathrm{VARIABLES} * * * * * * * * * * * * * * * * * * * * * *$

$* * * * * * *$ Options etc $* * * * * * * * * * * * * * * * * * * * * * * * * * * * * * * * * * * * * *$

rho0 $11000000000 \mathrm{Iz}$

observed_spins $1234567891011 \mathrm{Iz}$

EulerAngles rep100.dat

n_gamma 10

line_broaden $(\mathrm{Hz}) *$

zerofill *

FFT_dimensions *

cross87_d.cor

$8.207-0.698-0.686 \mathrm{H} 7 \mathrm{a}(\mathrm{CH} 2$ - molecule A) 


$$
\begin{aligned}
& 8.5540 .898-1.274 \mathrm{H} 7 \mathrm{~b}(\mathrm{CH} 2-\mathrm{A}) \\
& 7.0340 .2601 .303 \mathrm{H} 8(\mathrm{CH}-\mathrm{A}) \\
& 5.9761 .412-1.213 \mathrm{Ha}(\mathrm{NH} 3-\mathrm{A}) \\
& 5.1690 .8830 .100 \mathrm{Hb}(\mathrm{NH} 3-\mathrm{A}) \\
& 5.951-0.187-0.894 \mathrm{Hc}(\mathrm{NH} 3-\mathrm{A}) \\
& 10.6301 .831-0.798 \mathrm{H} 4(\mathrm{CHring}-\mathrm{A}) \\
& 9.091-1.1541 .852 \mathrm{H} 5(\mathrm{CHring}-\mathrm{A}) \\
& 9.394-2.663-0.444 \mathrm{H} 2(\mathrm{CHring} \text { inter - C) } \\
& 9.253-1.154-3.245 \mathrm{H} 5(\mathrm{CHring} \text { inter - B) } \\
& 7.1960 .260-3.793 \mathrm{H} 8 \text { (CH - B) }
\end{aligned}
$$



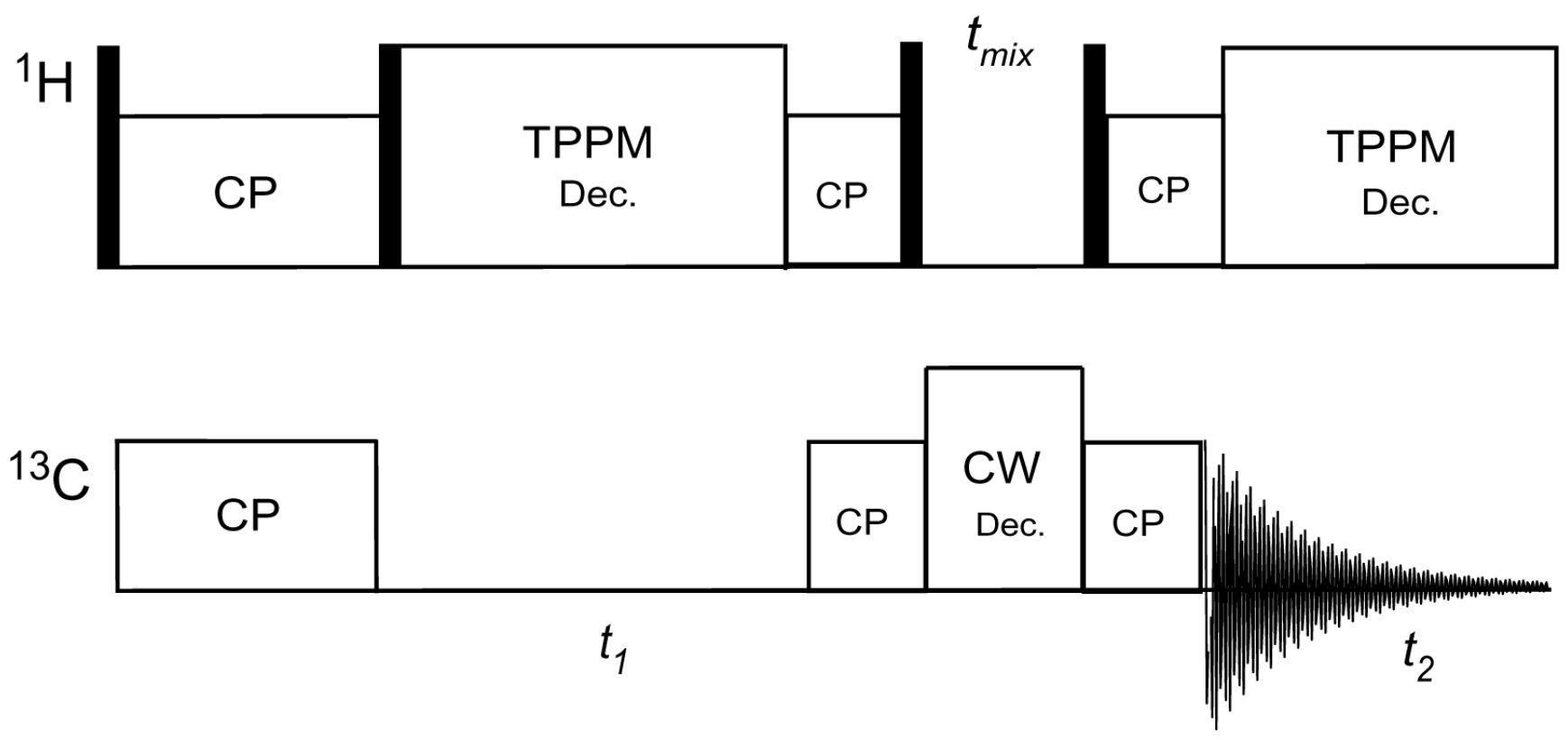

Fig. 1.

The CHHC pulse sequence employed in the present work, where, in addition to previous implementations, a $60 \mathrm{kHz}$ continuous-wave decoupling field is applied on the ${ }^{13} \mathrm{C}$ channel, in order to reduce the negative influence of the ${ }^{13} \mathrm{C}-{ }^{1} \mathrm{H}$ dipolar interaction upon the efficiency of ${ }^{1} \mathrm{H}-{ }^{1} \mathrm{H}$ magnetization exchange during the mixing time. 
<smiles>[NH3+]C(Cc1ccc(O)cc1)C(=O)O</smiles>
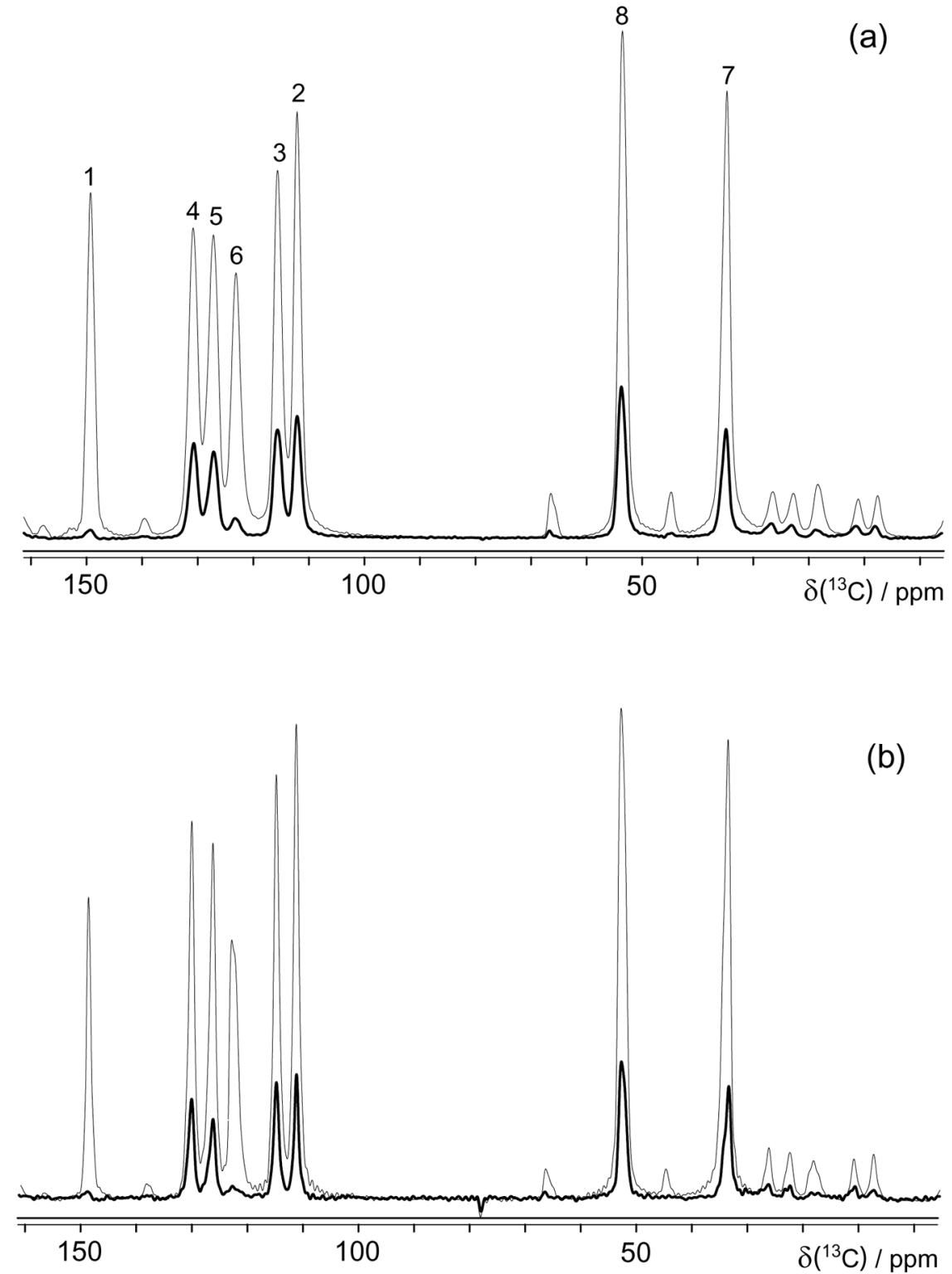

Fig. 2.

A comparison of ${ }^{13} \mathrm{C} \mathrm{CP}$ MAS (thin line) and ${ }^{13} \mathrm{C} \mathrm{CHHC}-$ filtered $\left(t_{l}=t_{\text {mix }}=0, \tau_{\mathrm{CP}}=65 \mu \mathrm{s}\right.$ for the last two CP steps) spectra (thick line) for (a) $\mathrm{U}_{-}{ }^{13} \mathrm{C}$ and (b) $\mathrm{U}_{-}{ }^{13} \mathrm{C}^{\text {dil__}}{ }^{10 \%} \mathrm{~L}$ Tyrosine $\cdot \mathrm{HCl}$. The contact pulse for the first $\mathrm{CP}$ step in the CHHC experiment (and the only $\mathrm{CP}$ step in the CP MAS experiment) was of duration $700 \mu \mathrm{s}$. For both experiments, $32\left(\mathrm{U}-{ }^{13} \mathrm{C}\right.$ ) and 256 (U- ${ }^{13} \mathrm{C}^{\mathrm{dil}}{ }^{10 \%}$ ) transients were co-added for a recycle delay of $3 \mathrm{~s}$. 

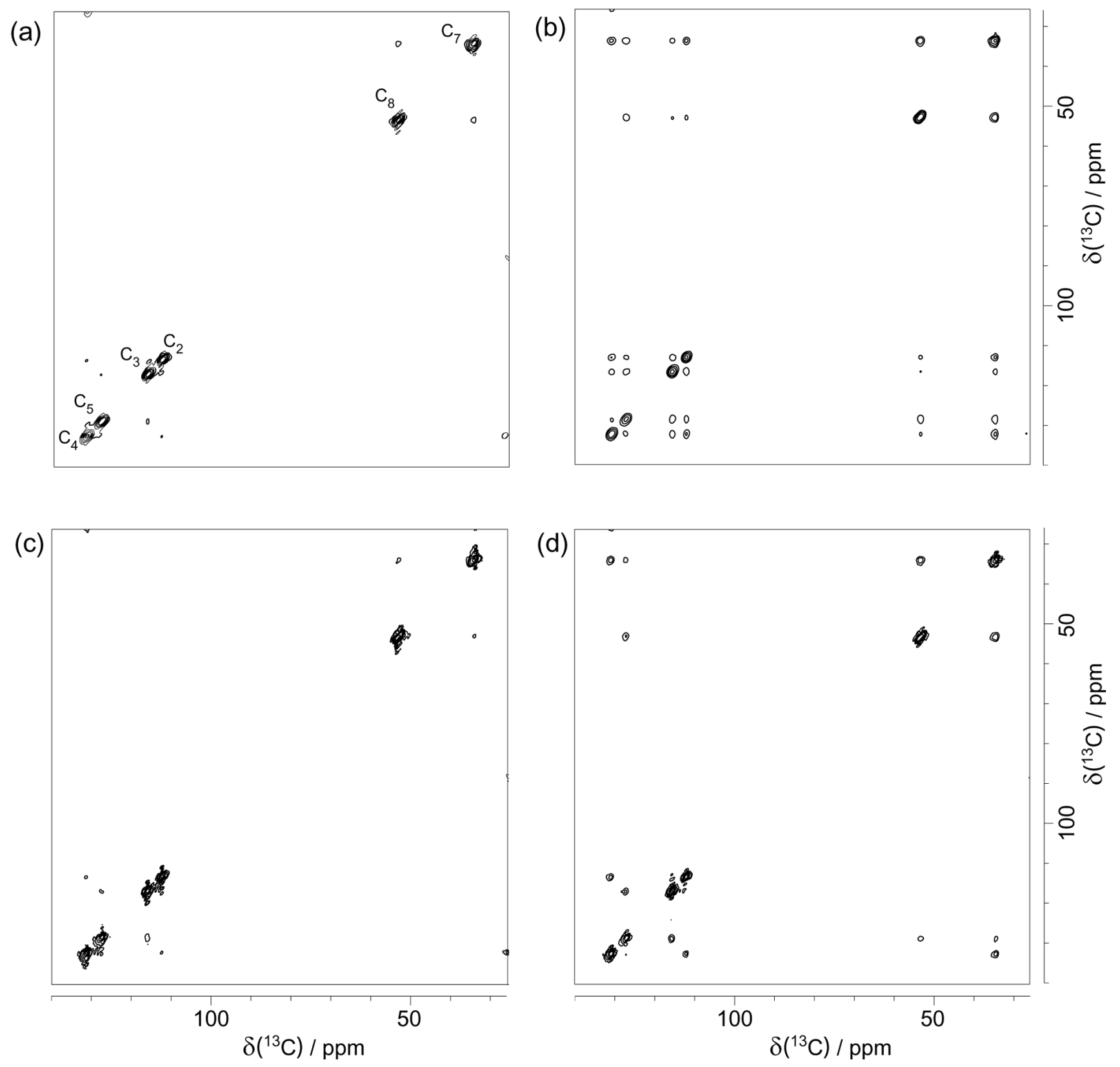

Fig. 3.

2D CHHC spectra of (a,b) U- ${ }^{13} \mathrm{C}$ and $(\mathrm{c}, \mathrm{d}) \mathrm{U}-{ }^{13} \mathrm{C}^{\text {dil__}}{ }^{10 \%} \mathrm{~L}$-Tyrosine $\cdot \mathrm{HCl}$ recorded with $t_{\text {mix }}$ equal to $(\mathrm{a}, \mathrm{c}) 0$ and $(\mathrm{b}, \mathrm{d}) 100 \mu \mathrm{s}$. The base contour level is at $3 \%$ and $5 \%$ for the two different mixing times. 
(a)
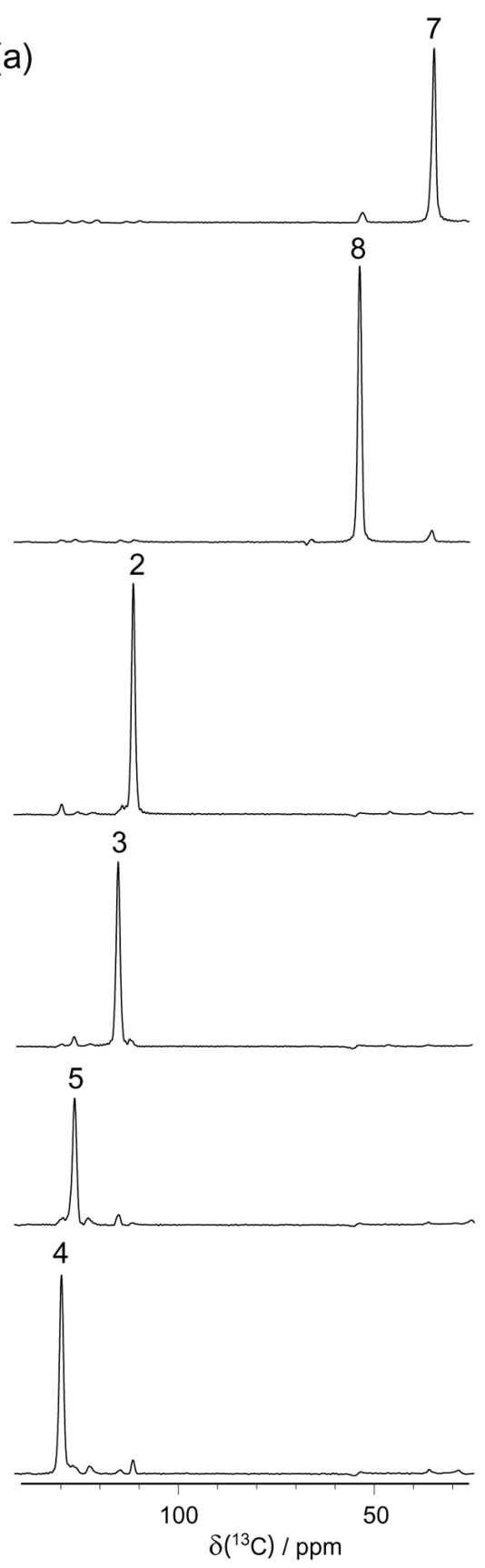

(b)

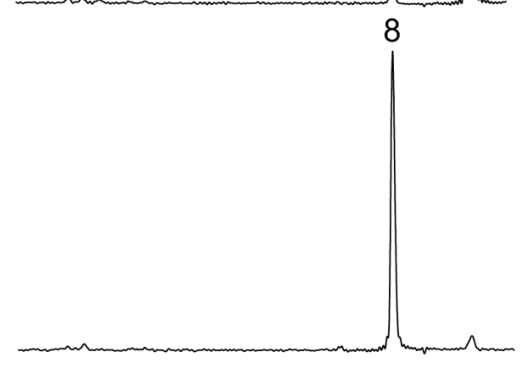

2
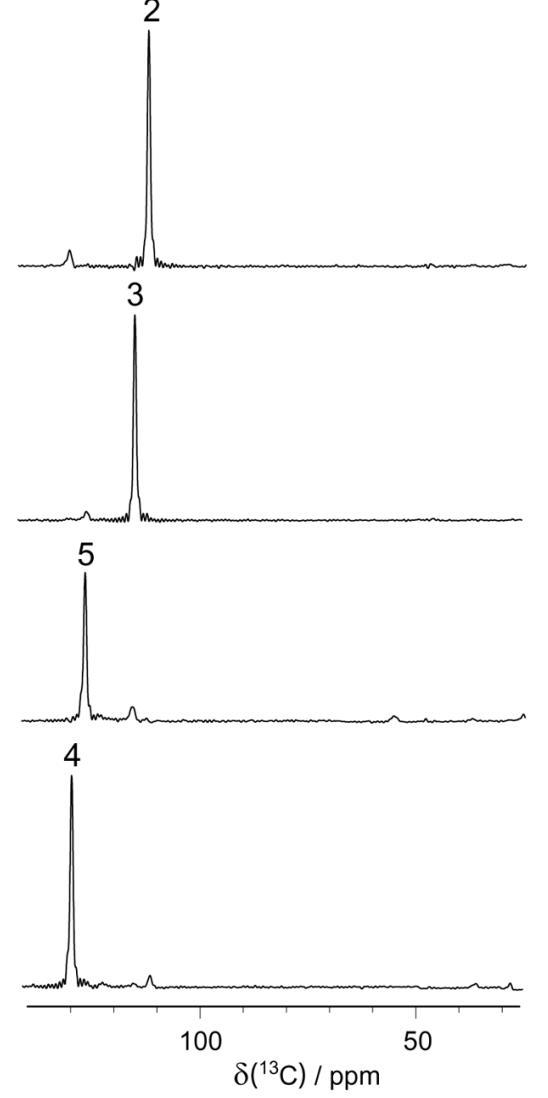

Fig. 4.

Rows extracted from the 2D CHHC spectra (see Fig. 3(a) and (c)) of (a) $\mathrm{U}^{13} \mathrm{C}$ and (b) $\mathrm{U}-{ }^{13} \mathrm{C}^{\text {dil_}} 10 \% \mathrm{~L}$-Tyrosine. $\mathrm{HCl}$ recorded with $t_{\text {mix }}$ equal to $0 \mu \mathrm{s}$. 

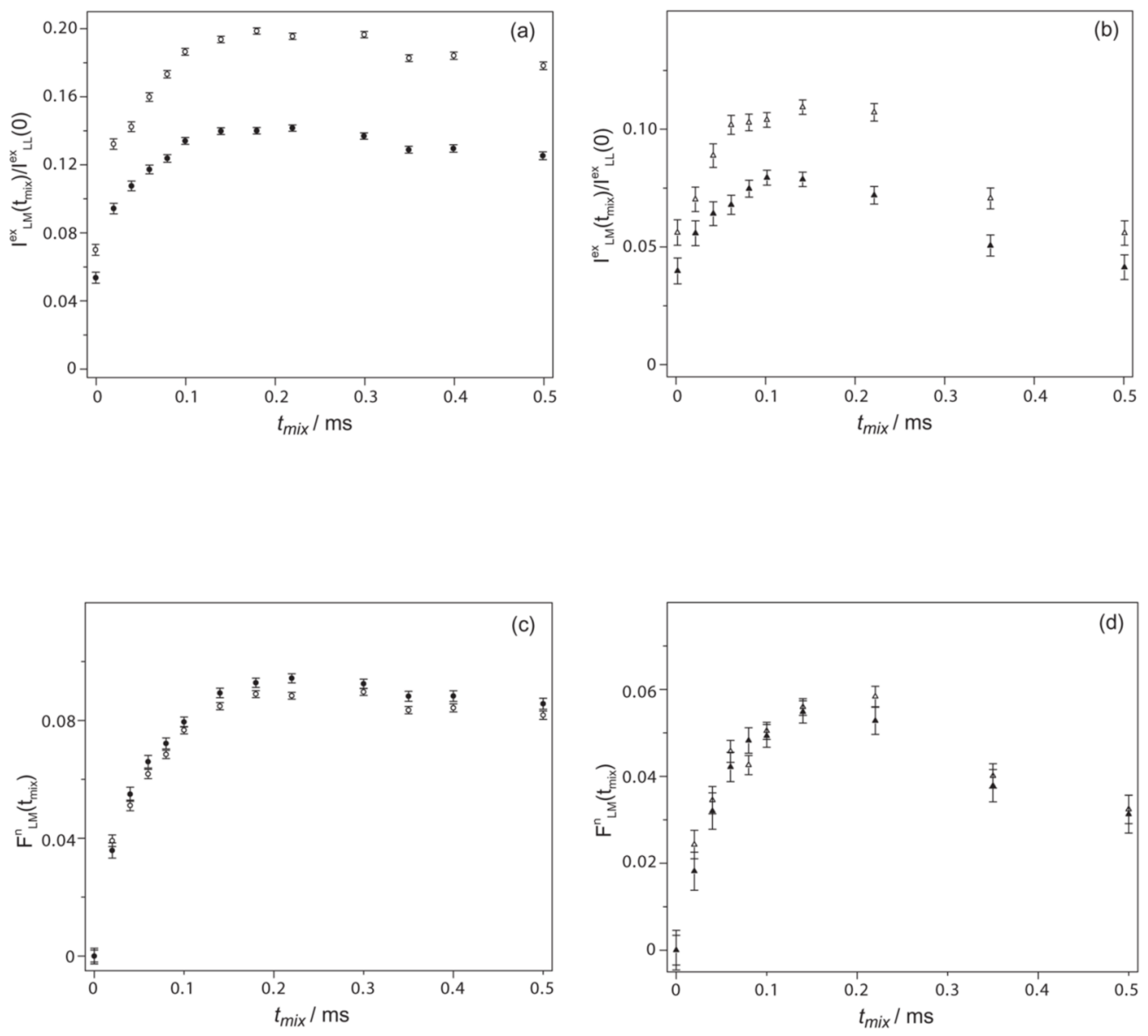

Fig. 5.

The buildup of $\mathrm{C} 7\left({ }^{\beta} \mathrm{CH}_{2}\right)$ to $\mathrm{C} 8\left({ }^{\alpha} \mathrm{CH}\right)$ (open symbols) and $\mathrm{C} 8$ to $\mathrm{C} 7$ (filled symbols) crosspeak intensity as a function of $t_{\mathrm{mix}}$ for $(\mathrm{a}, \mathrm{c}) \mathrm{U}-{ }^{13} \mathrm{C}$ and $(\mathrm{b}, \mathrm{d}) \mathrm{U}_{-}{ }^{13} \mathrm{C}^{\mathrm{dil}}{ }^{10 \%} \mathrm{~L}$-Tyrosine.HCl. In (a) and (b), the cross-peak intensities are normalized with respect to the intensity of the corresponding diagonal peak for zero mixing time, i.e., $I_{L M}^{e x}\left(t_{m i x}\right) / I_{L L}^{e x}(0)$. In the case of the $\mathrm{U}-{ }^{13} \mathrm{C}^{\text {dil_}}{ }^{10 \%}$ sample, a scaling by the factor $\lambda$ as defined in Eq. (27) of 0.91 was applied to $I_{L L}^{e x}(0)$. (c) and (d): corrected normalized buildup plots given by $F_{L M}^{n}\left(t_{m i x}\right)$ as defined in Eqs. (19) \& (28) of Section 3.2. Tables 1 and 2 list the $\eta_{L}$ and $\varepsilon_{L M}$ coefficients. 

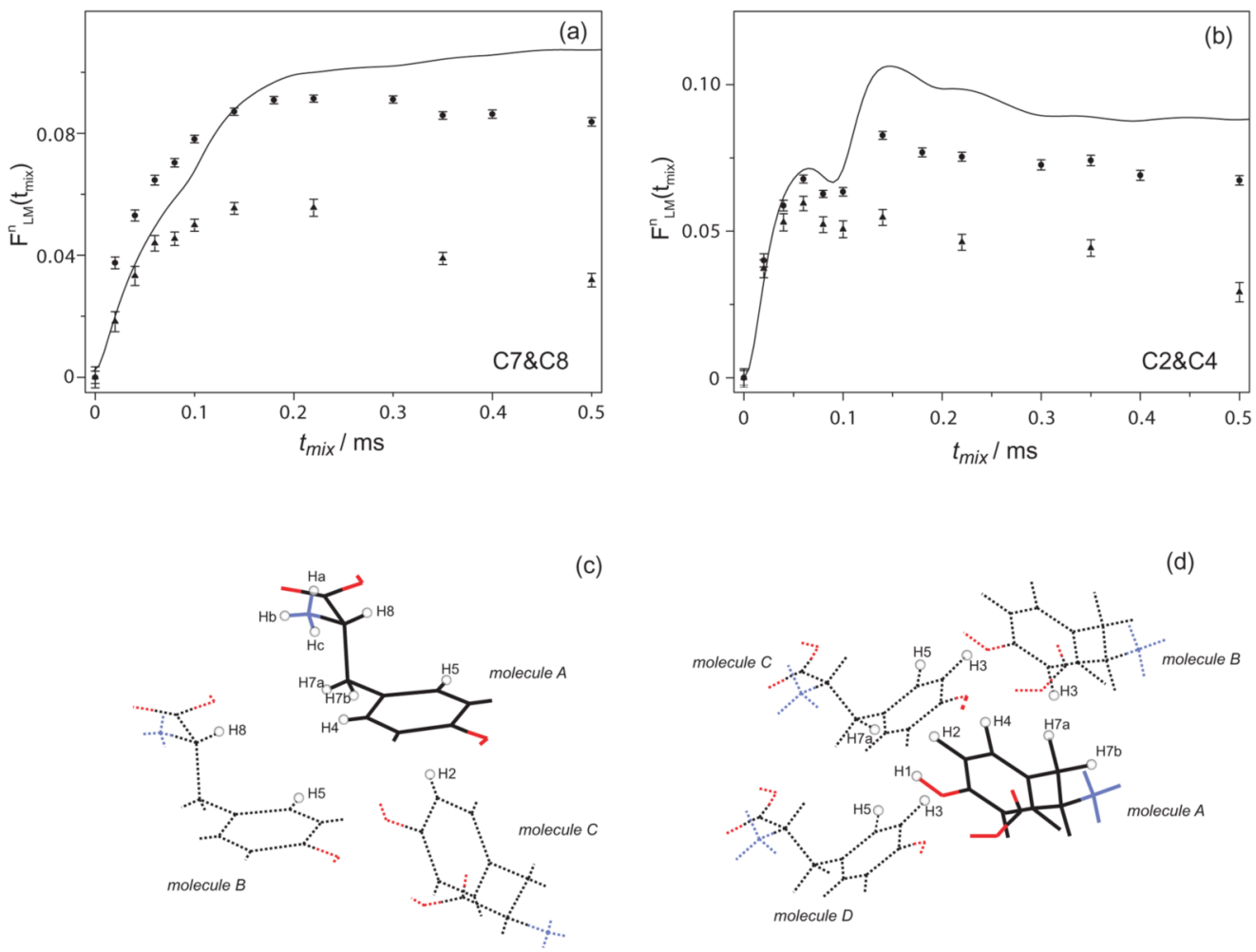

Fig. 6.

Comparison between the corrected normalized experimental CHHC buildup curves, i.e., $F_{L, M}^{n}\left(t_{m i x}\right)$ as defined in Eqs. (19) \& (28), for $\mathrm{U}^{13} \mathrm{C}$ (circles) and U- ${ }^{13} \mathrm{C}^{\text {dil_10\% }}{ }^{10 \%}$ (triangles) $L-$ Tyrosine $\cdot \mathrm{HCl}$ for (a) $\mathrm{C} 7-\mathrm{C} 8$ and (b) $\mathrm{C} 2-\mathrm{C} 4$. The solid lines in (a) and (b) correspond to SPINEVOLUTION density-matrix simulations of $F_{L M}^{n}\left(t_{m i x}\right)$ (see Eq. (4)) for 11 spin systems centered around $\mathrm{H} 7, \mathrm{H} 8$ and $\mathrm{H} 2, \mathrm{H} 4{ }^{1} \mathrm{H}$ nuclei as illustrated in (c) and (d), respectively. 


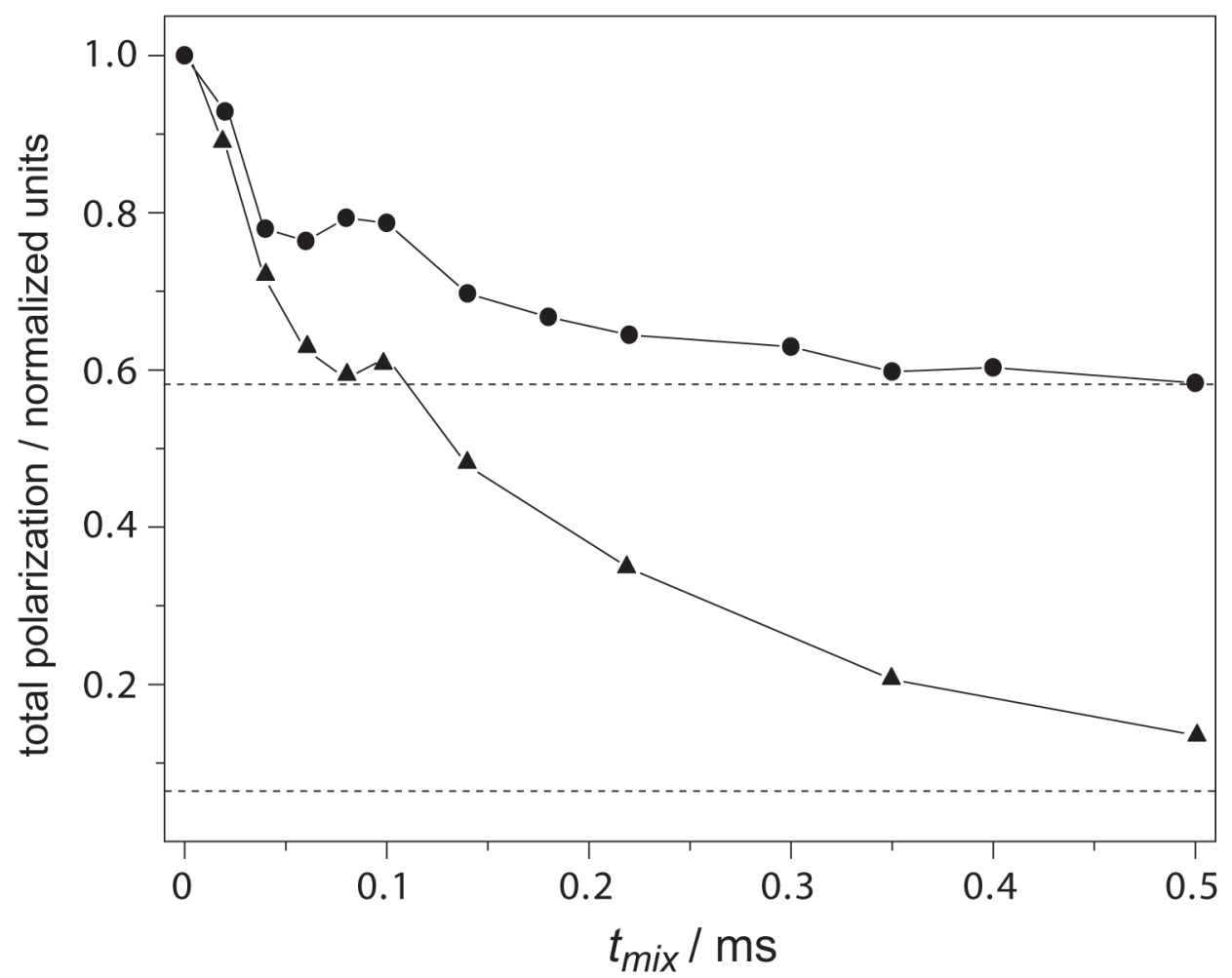

Fig. 7.

The evolution with the $\mathrm{CHHC}$ mixing time of the total $\mathrm{C} 7$ polarization in the $\mathrm{U}^{-13} \mathrm{C}$ (circles) and $\mathrm{U}_{-}{ }^{13} \mathrm{C}^{\text {dil_}} 10 \%$ (triangles) $L$-Tyrosine $\cdot \mathrm{HCl}$ samples, considering an initial state of unit polarization. The total polarization is expected to trend towards $N_{\text {obs }} / N_{\text {tot }}=7 / 12=0.58$, and $7 / 120=0.06$ for the $\mathrm{U}^{13} \mathrm{C}$ (circles) and $\mathrm{U}_{-}{ }^{13} \mathrm{C}^{\text {dil_}}{ }^{10 \%}$ samples, respectively (see horizontal dashed lines). 

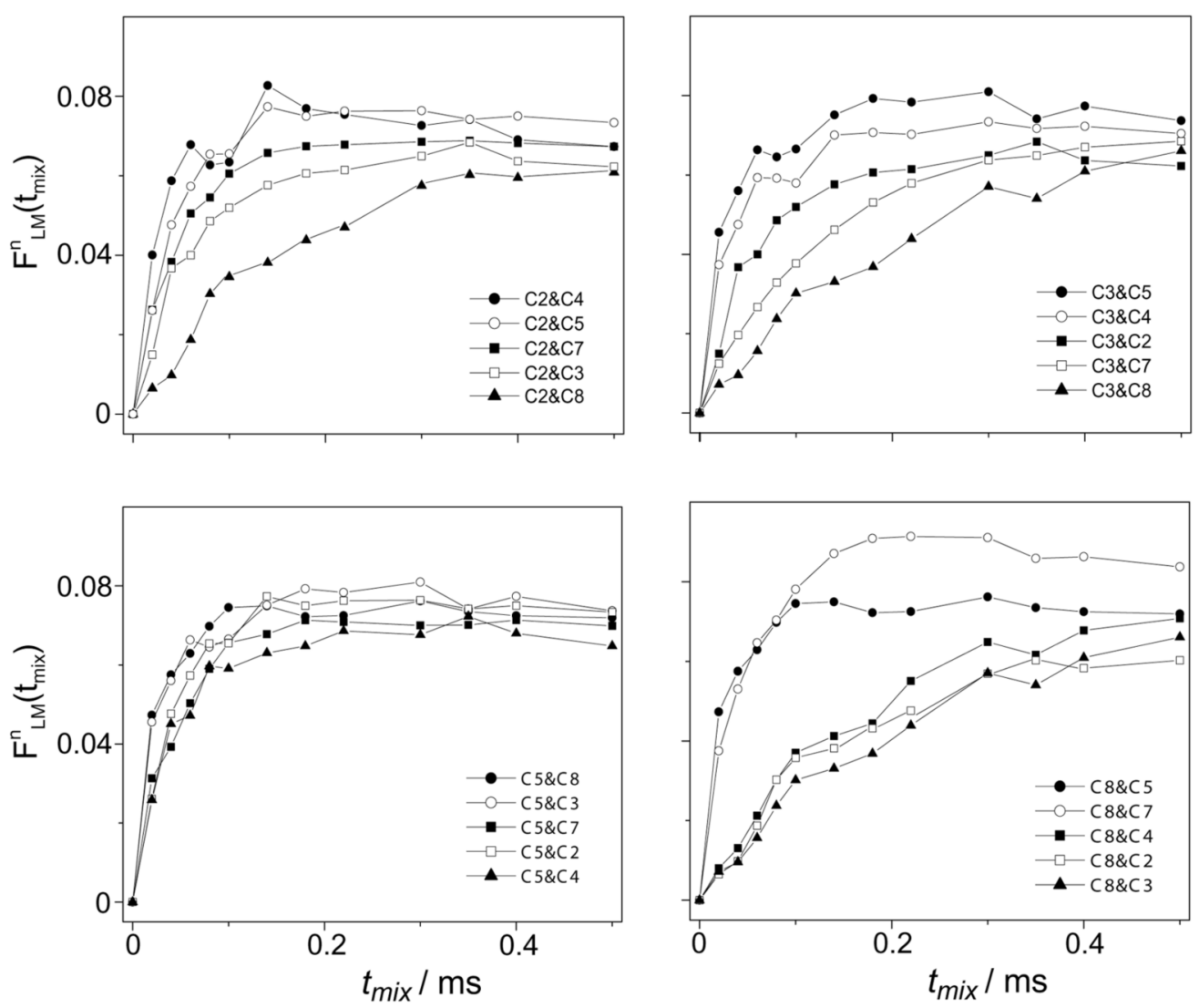

Fig. 8.

Corrected normalized experimental CHHC buildup curves corresponding to $F_{L, M}^{n}\left(t_{m i x}\right)$ as defined in Eq. (19) for $\mathrm{U}^{13} \mathrm{C} L$-Tyrosine $\cdot \mathrm{HCl}$ for magnetization starting on (a) $\mathrm{C} 2$, (b) $\mathrm{C} 3$, (c) C5 and (d) C8. 

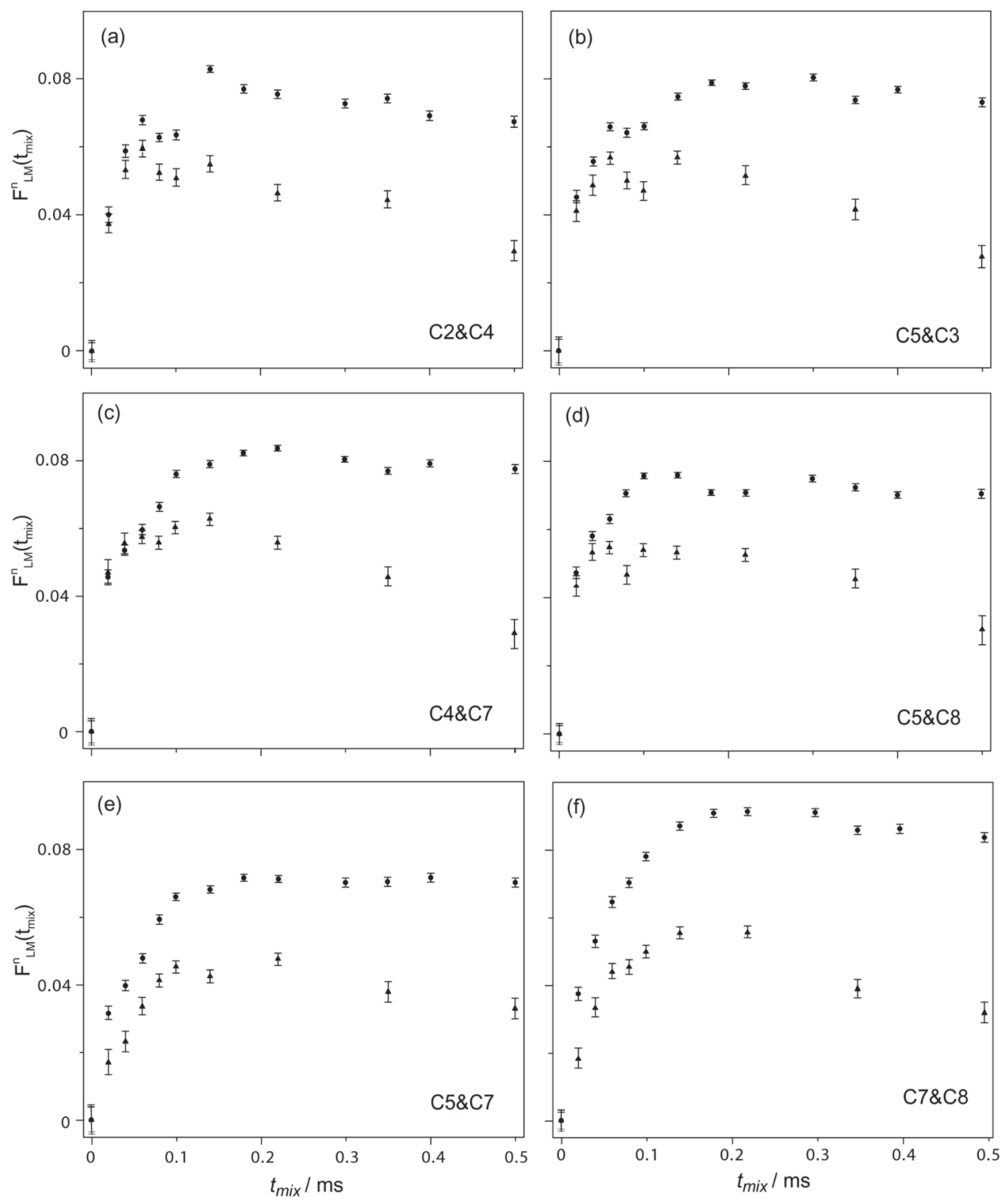

Fig. 9.

Comparison between the corrected normalized experimental CHHC buildup curves, i.e., $F_{L, M}^{n}\left(t_{m i x}\right)$ as defined in Eqs. (19) \& (28), for $\mathrm{U}^{13} \mathrm{C}$ (circles) and U- ${ }^{13} \mathrm{C}^{\text {dil_10\% }}{ }^{10 \%}$ (triangles) $L-$ Tyrosine $\cdot \mathrm{HCl}$ for (a) C2-C4, (b) C3-C5, (c) C4-C7, (d) C5-C8, (e) C5-C7 and (f) C7-C8. 


\section{Table 1}

The experimental $\eta_{L}$ parameters evaluated using Eq. (22) for the specified ${ }^{13} \mathrm{C}^{L}$ sites in $L$-Tyrosine. $\mathrm{HCl}$. $\eta_{L}\left(\mathrm{U}_{-}{ }^{13} \mathrm{C}\right) \eta_{L}\left(\mathrm{U}_{-}^{13} \mathrm{C}^{10 \% \_d \mathrm{dr}}\right)$

\begin{tabular}{|l|l|l|}
\hline $\mathrm{C} 7$ & $0.66 \pm 0.01$ & $0.63 \pm 0.03$ \\
\hline
\end{tabular}

\begin{tabular}{|l|r|r|}
\hline C $8.52 \pm 0.52 \pm 0.01$ & $0.50 \pm 0.02$ \\
\hline
\end{tabular}

\begin{tabular}{l|l|l|}
\hline C2 2 & $0.51 \pm 0.01$ & $0.51 \pm 0.03$ \\
\hline
\end{tabular}

\begin{tabular}{|l|l|l|}
\hline C 3 & $0.52 \pm 0.01$ & $0.51 \pm 0.02$ \\
\hline
\end{tabular}

\begin{tabular}{l|l|l|}
\hline C 5 & $0.55 \pm 0.02$ & $0.54 \pm 0.03$ \\
\hline C $40.53 \pm 0.01$ & $0.52 \pm 0.04$ \\
\hline
\end{tabular}

\begin{tabular}{|l|l|l|l|l|l|l}
\hline C $40.53 \pm 0.01$ & $0.55 \pm 0.04$ & $0.52 \pm 0.04$ \\
\hline
\end{tabular}




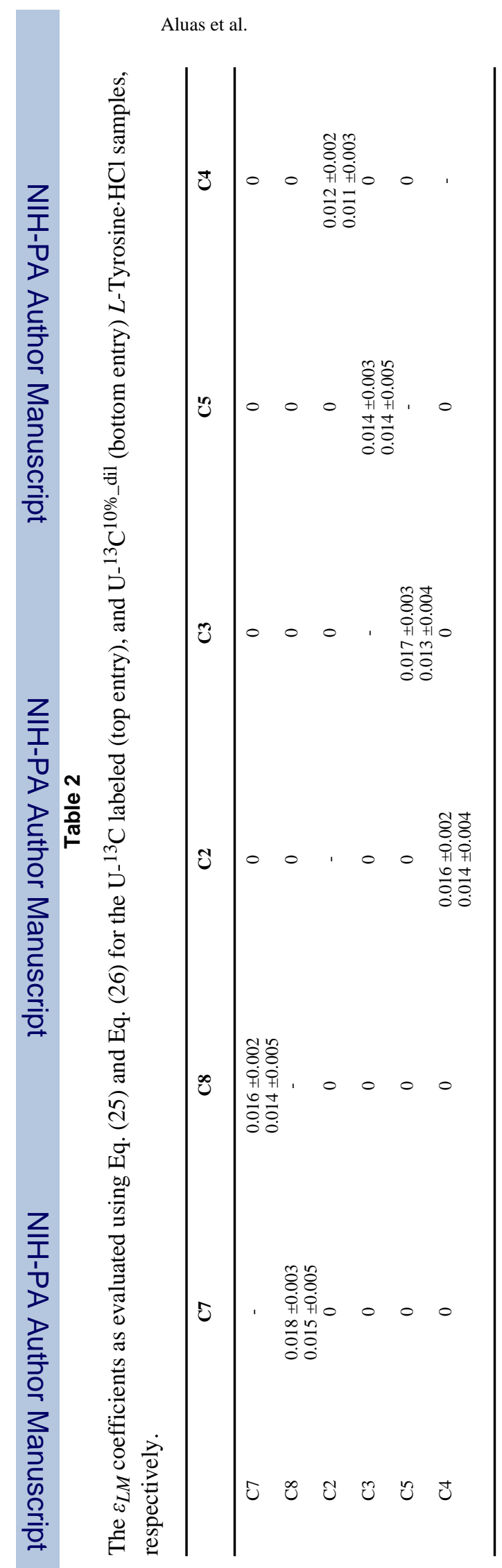

Page 30 


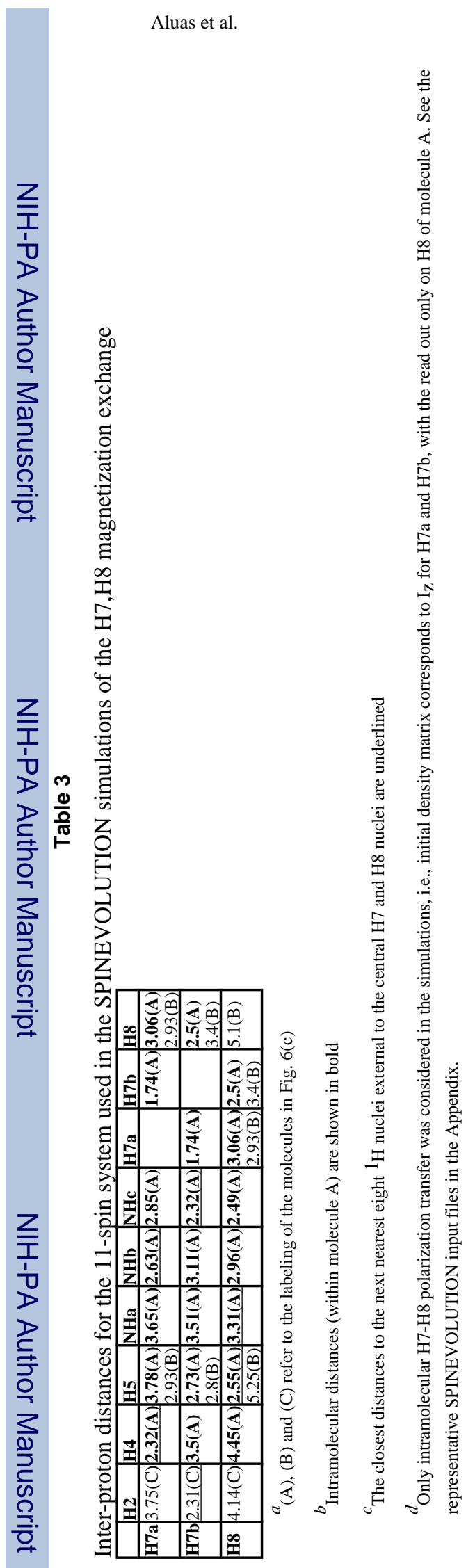

J Magn Reson. Author manuscript; available in PMC 2010 August 1. 


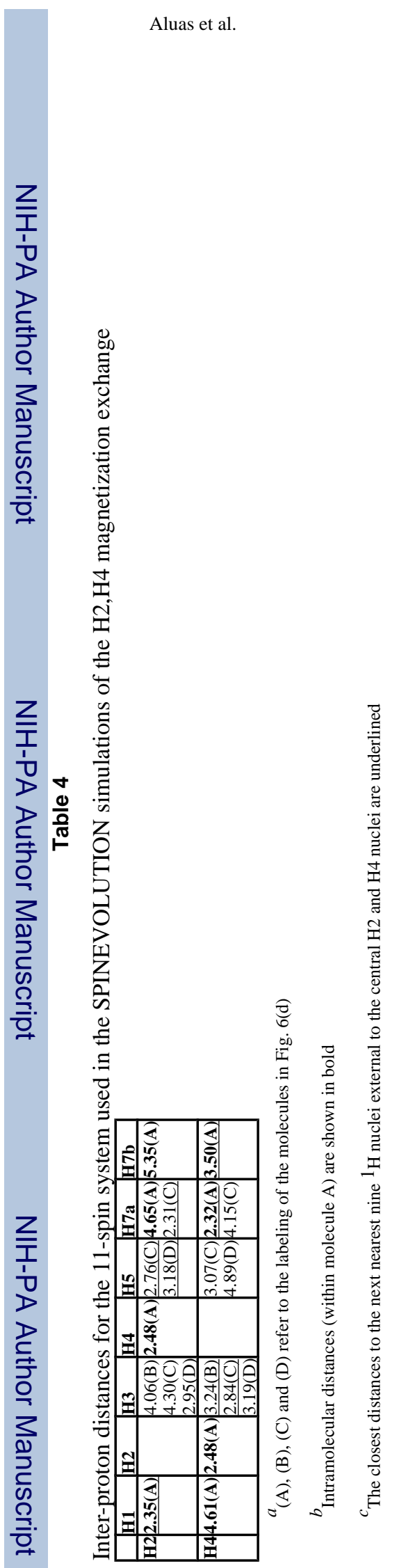

J Magn Reson. Author manuscript; available in PMC 2010 August 1. 
1
0
0

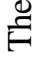

둥

क
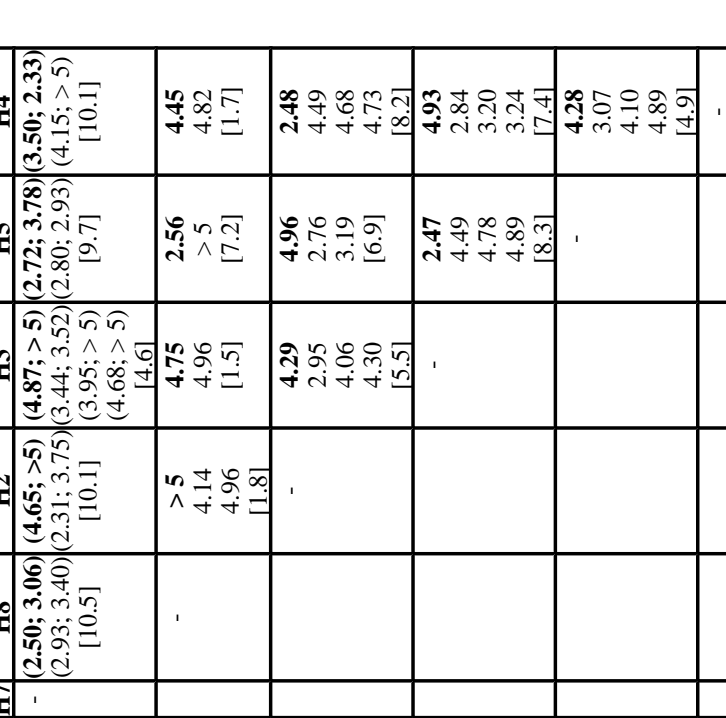

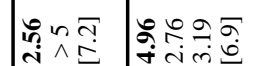

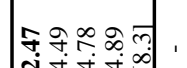

ì $\stackrel{+}{+}+\dot{+}+\infty$

वतल

